\title{
FIESTAS Y LA ECONOMÍA POLÍTICA WARI EN MOQUEGUA, PERÚ
}

\author{
FEASTING AND THE WARI POLITICAL ECONOMY IN MOQUEGUA, PERU
}

\author{
Donna Nash ${ }^{1}$
}

\begin{abstract}
Las fiestas se han considerado componentes importantes en las actividades políticas de los Estados arcaicos. En los sitios Wari de Cerro Baúl y Cerro Mejía, ubicados en el valle de Moquegua en la periferia sur del Estado, se han encontrado varios lugares de reunión y áreas de preparación para fiestas. Se registraron evidencias de preparación de elaboradas comidas para rituales importantes, encuentros sociales y establecer lazos políticos, jerarquías y contratos sociales. Las comidas festivas y ajuares relacionados varían dependiendo del contexto y dimensión política. Este artículo propone una aproximación comparativa para diferenciar los marcadores arqueológicos de las fiestas celebradas en diferentes lugares de reunión y su relación con el control político del Estado Wari.
\end{abstract}

Palabras claves: economía política, Wari, imperios, hogares, fiestas, arqueología de Moquegua.

Feasting is currently considered a significant component of political activities in archaic states. Several feasting venues and associated preparation areas have been recovered from the Wari sites of Cerro Baúl and Cerro Mejía on the State's southern periphery in the Moquegua Valley of Peru. Elaborate meals were prepared for important ritual and social gatherings and established social contracts, political ties, and hierarchies. Feast meals and accoutrements varied depending on their context. This article takes a comparative approach to illuminate the archaeological markers of feasting in different venues and its relationship to political control in the Wari State.

Key words: Political economy, Wari, empire, houses, feasting, archaeology of Moquegua.

En recientes publicaciones los arqueólogos andinos han reconocido la importancia de las fiestas como eventos de congregación de personas (Kaulicke y Dillehay 2005). Estas pudieron jugar un rol significativo en el desarrollo de complejas formaciones políticas, debido a que dichos eventos estuvieron donde las relaciones de poder fueron establecidas, mantenidas y renegociadas (Cook y Glowacki 2003; Gero 2001; Morris y Thompson 1985). Las reuniones festivas de variadas formas y tamaños, a menudo, incluyen la preparación y consumo de comidas especiales. Estas reuniones sociales son comúnmente llamadas fiestas. Las características principales de éstas y las evidencias asociadas a ellas, de manera comparativa, podrían revelar una importante dimensión en las relaciones sociopolíticas de antiguas sociedades, así como las prominentes instituciones en los orígenes de los Estados andinos tempranos.

Los investigadores interesados en comparaciones interculturales han creado un número de esquemas tipológicos para definir las fiestas, sin embargo, un único evento puede ser el lugar para diferentes tipos de relaciones sociales. En particular, muchos investigadores han encontrado útiles las categorías de fiesta definidas por Dietler (2001; Dietler y Herbich 2001) para el entendimiento de las relaciones de poder. Entre ellas, "fiestas de trabajo" (work feast) y "fiestas con patrocinador" (patron-role feasts) figuran prominentemente entre los modelos actuales de la economía política andina. Las "fiestas de trabajo" (ver Dietler y Herbich 2001) congregan personas para lograr una meta y cambio de su trabajo son alimentadas por un patrocinador. Dichas "fiestas de trabajo" constituyen un elemento significativo en los modelos teóricos empleados para describir los proyectos de construcción Inka y otros aspectos de la producción estatal (Morris 1985; Moseley 1992; Rostworowski 1999; Rowe 1946, 1982). Incluso las "fiestas de trabajo" son difíciles de identificar en el registro arqueológico porque, a menudo, dichas fiestas son producidas y consumidas en un establecimiento temporal o al aire libre.

1 Departamento de Antropología, Universidad de North Carolina Greensboro, 439 Graham Building, PO Box 26170, Greensboro, North Carolina, 27402,EE.UU. djnash@uncg.edu 
Las obligaciones laborales creadas a partir de la realización de "fiestas con patrocinador" (ver Dietler 2001) y representadas en espacios públicos por el Inka, también son descritas como una fuente de poder a través de las cuales las élites gobernantes acumularon excedentes y riqueza (D'Altroy 2001; D'Altroy y Earle 1985; Morris 1982; Murra 1980, 1982). Las “fiestas con patrocinador" son realizadas por élites para legitimar y mantener las relaciones asimétricas de explotación y extracción entre los administradores y la población (Isbell 1997; Kolata 2003a). La diferencia entre una "fiesta de trabajo" y una "fiesta con patrocinador" está asociada a las relaciones sociales entre los anfitriones y los invitados. Las "fiestas de trabajo" sólo pueden establecer vínculos temporales asimétricos entre anfitriones e invitados, en otra oportunidad un invitado puede convertirse en anfitrión. Por otro lado, las "fiestas con patrocinador" son caracterizadas por una relativa permanencia en las relaciones asimétricas donde el rol del patrocinador y del cliente es establecido y mantenido. Las "fiestas patrocinadas" pueden ser más visibles arqueológicamente, porque pueden celebrarse en grandes áreas ceremoniales, en pequeños espacios semipúblicos, o en áreas diseñadas con cocinas para continuas reuniones y otras características necesarias localizadas en los alrededores (por ejemplo: almacenes). Las grandes plazas de las ciudadelas de Chan Chan son un buen ejemplo de un área semipública. De hecho, cualquier palacio debería haber contado con esta área (ver Evans 2004).

Los palacios también constituyen un lugar para otro tipo de fiestas denominadas "fiestas distinguidas". De acuerdo con Dietler (2001), son aquellas que pueden tener comidas especiales, sofisticados menajes de servicio, así como el conocimiento de ciertos valores o comportamientos (por ejemplo, etiqueta). La participación en una "fiesta distinguida" define a los individuos como miembros de un grupo exclusivo. Puede ser el lugar donde se desarrollan competencias entre élites, empleando las más elaboradas demostraciones de riqueza y estatus o definidas por el lugar especial en que se llevan a cabo.

Dietler (2001) enfatiza la importancia de las fiestas como una forma de ritual y resalta que cualquiera puede tener una dimensión distinguida. Estas tres categorías: fiestas de trabajo, fiestas con patrocinador y fiestas distinguidas, se superponen en muchas formas y son modalidades de celebración en vez de tipos de fiestas en las que se enfatizan los procesos políticos. Esas distinciones destacan las estrategias de ciertos individuos para generar y mantener poder, sin embargo, también tienen dimensiones sociales más sutiles. Las fiestas, reuniones en las que se comparten alimentos, pueden crear un nexo entre los participantes. Inclusive comidas cotidianas pueden iniciar prácticas y crear disposiciones (Bourdieu 1990; Dietler 2001). Dietler y Hayden (2001) discuten los elementos socializadores de las fiestas, los cuales pueden tener importantes implicaciones para una política en expansión. Wiessner (2001) distingue entre comida entregada (fiestas seculares) y comida consumida en una atmósfera de comensales (fiestas sacras), donde el compartir alimentos en una atmósfera de celebración, música y ritos sagrados permite la creación de fuertes lazos afectivos a nivel de grupo. El evento, la reunión de personas, la fraternidad y el compartir alimentos y experiencias hacen de las fiestas un importante acontecimiento sociopolítico.

Dietler (2001) define esta perspectiva como simple y funcionalista; sin embargo, admite que las fiestas pueden ser una manera efectiva para unir a las personas. Sugiero que en un contexto imperial, con múltiples grupos étnicos, cuyos líderes deben relacionarse con emisarios de la política dominante, la creación de tales lazos habría sido muy importante, y quizás no fue fácil de alcanzar. La creación de vínculos entre los administradores conquistados y los administradores conquistadores fue esencial para la cohesión política y la consolidación de ésta. Las fiestas, a la manera Wari, pudieron llegar a ser una práctica compartida. En su vida diaria los miembros del imperio expresaron ampliamente diferentes tecnologías. Sin embargo, si el Estado auspiciaba reuniones festivas regularmente la gente pudo haber creado lazos a través del tiempo, independientemente de sus diferencias étnicas. Aquellos individuos, comúnmente limitados a élites locales o líderes comunales que compartían dichas experiencias podrían llegar a practicar una singular tradición festiva (si escogían cooperar y participar con el Estado Wari). Las fiestas de pequeños grupos de funcionarios en un número de niveles en el Imperio Wari pudieron haber sido una importante forma de mantener la política unida y construir lazos entre los líderes locales y los líderes Wari. Pequeñas "fiestas distinguidas" o más apropiadamente "fiestas de cohesión" pudieron ser una importante forma de extender la 
ideología imperial y de unificar algunos aspectos de la economía política del Estado.

Para evaluar el rol de las fiestas o reuniones festivas en la economía política de una sociedad antigua resulta primordial entender las evidencias arqueológicas correspondientes a la preparación diaria de alimentos y cómo las fiestas exceden dichas normas. El énfasis en fiestas se ha enfocado, principalmente, en el consumo y en las correspondientes relaciones de los comensales. Para entender dichos procesos son igualmente importantes los medios por los cuales estos alimentos son preparados y las relaciones que proporcionan los recursos para celebrar el evento. Es posible que los líderes de bajo nivel fueran dependientes en sus relaciones con el Estado o con su mando inmediato superior para obtener los recursos necesarios para realizar una fiesta, especialmente si en sus casas no hay o es poco el espacio para almacenaje. Las élites de bajo nivel actuando en beneficio del Estado también pudieron ser dependientes de los canales de éste para obtener los objetos símbolos de poder, o demostraciones de prestigio, especialmente si la evidencia para la producción de dichos bienes fue limitada a establecimientos estatales. Todos esos factores son importantes.

\section{Modelos de Fiesta Andina}

Los modelos de administración andina basados en fiestas se sustentan en la etnografía y en las crónicas de las prácticas del Estado Inka. En los registros etnohistóricos del Inka se describen ceremonias a gran escala, tales como el Inti Raymi, que restablecía lealtades en intervalos regulares (Garcilaso de la Vega 1966 [1609]). Dichas ceremonias también establecían la importancia religiosa del Inka y la legitimación de las relaciones asimétricas de poder. Este festival anual, a menudo realizado en Cusco, o donde el Sapa Inka se hallara, congregaba élites de todo el dominio Inka. Aunque se ha dado mucho énfasis en el Inka y sus gastos, también es importante reconocer que las élites visitantes traían consigo regalos de muchos tipos. Es posible también que estas fiestas, y muchas otras, sirvieran para facilitar el intercambio y las interacciones políticas. El esquema de las reuniones pudo haber sido diseñado tanto por los invitados como por el anfitrión, o basarse intencionalmente en convenciones compartidas. La repetición de estas fiestas fomentaba la unión entre líderes y los envolvía en una experiencia conjunta. Las festividades de este tipo definían a los participantes como miembros de la élite estatal y promovían la unidad a través de la práctica de ritos sagrados, el compartir alimentos y la celebración.

El Inka también alimentaba grandes grupos de pobladores durante sus proyectos; algunas crónicas describen que proporcionó comida, así como casa, ropa y herramientas para aquellos que servían al Estado (Betanzos 1987 [1557]; Guamán Poma de Ayala 1980 [1615]). Existe escasa información al respecto y no es claro cómo dichas comidas fueron provistas a los trabajadores; sin embargo, Cieza de León (1959 [1553]:163) relata que al menos en el caso de los mineros fueron sus esposas quienes las preparaban. De hecho, sólo los hombres casados podían ser enviados a las minas porque era responsabilidad de las esposas cocinar sus alimentos en este tipo de mit'a. Definitivamente, ésta es una situación diferente. Incluso si la comida repartida era especial o abundante (por ejemplo, que incluyera chicha), o si los trabajadores la consumían en albergues individuales en vez de grupos, en una atmósfera donde compartían sus alimentos, esta "fiesta" de alimentos no conlleva el mismo efecto sociopolítico de una fiesta que, a la vez, es una "reunión festiva".

Si el intercambio de alimentos por trabajo no hubiera incluido una comida preparada en un establecimiento estatal o en una gran cocina común localizada en el área de trabajo, entonces ¿podría ser considerada una fiesta? La diferencia es importante. Una gran fiesta pública pudo haber estado asociada con el inicio de una obligación original, incluso cuando la labor se realizaba en un lugar distante un número pequeño de fiestas, auspiciadas por el Estado a través de los líderes locales también, pudo servir para crear las mismas obligaciones. Las fiestas modestas no requerían de grandes espacios para recibir personas ni amplias cocinas para preparar los alimentos. Un sistema de pequeñas fiestas pudo ser implementado por un Estado o un imperio en crecimiento antes de que el poder se consolidara en la región. Un sistema de pequeñas fiestas puede ser más característico en un nuevo y expansivo Estado, con grandes fiestas ceremoniales desarrolladas mientras el imperio se fortalece. Alternativamente, un gobierno puede tener varias instituciones que se relacionan con fiestas en diferentes escalas y con reuniones grandes y pequeñas, ambas jugando un importante rol en la política estatal. El rol de las 
fiestas en el Imperio Wari no puede basarse sólo en las prácticas observadas posteriormente en grandes estados de segunda generación tales como el Inka; en vez de ello el entendimiento del rol de las fiestas requiere de una cuidadosa evaluación del registro arqueológico. Modelos de cómo las fiestas jugaron un rol en la economía política estatal deberían estar basados en evidencia arqueológica, en vez de inferencias de los registros españoles de un periodo más tardío.

Cocinas grandes y formales produciendo a gran escala para las "fiestas con patrocinador" deberían ser fáciles de reconocer en el registro arqueológico; el tamaño de las mismas puede ser usado para estimar el número de participantes. Si dichas cocinas han sido halladas, lamentablemente no han sido descritas con suficiente detalle para relacionarlas con grandes reuniones ceremoniales. La evidencia arqueológica de la interacción política entre comensales (comensal politics) en los Andes es más característica en la escala de reuniones relativamente pequeñas (ver Brewster-Wray 1989) o relacionada a depósitos rituales (ver Kolata 2003b). El patrocinio puede ser establecido entre líderes y subordinados en fiestas de cualquier tamaño. Es posible que reuniones a pequeña escala auspiciadas por el Estado y realizadas por los líderes locales sirvieran a varios propósitos y a la vez fueran un significante medio de relaciones sociopolíticas en la política Wari.

La producción y consumo de comidas especiales son comunes en descripciones etnográficas de comunidades andinas tradicionales y pueden haber sido igualmente importantes en la reproducción de la unidad doméstica en el pasado; sin embargo, todas esas ocasiones no son iguales al interior de las vidas de los anfitriones y de aquellos que las atienden (Dietler 2003). Aquellas actividades pueden constituir momentos importantes en la vida de los individuos, tales como nacimientos, matrimonios y muerte (Bolin 1998). De igual modo, pueden recordar sucesos a nivel político: tomas de mando, alianzas y ritual de cierre de recintos sagrados (Cieza de León 1959 [1553]). Esas ocasiones pueden ser usadas para establecer o reforzar las jerarquías sociales existentes, crear lazos en varias escalas y establecer obligaciones asimétricas. Los eventos festivos son celebrados de diferentes maneras por los miembros de la misma comunidad, basados en distintas identidades sociales. En algunos casos, los eventos pueden tener una cualidad de exclusión (Nash y Williams 2005) o pueden reforzar las diferencias sociales. Al mismo tiempo, unen a los participantes y pueden ser una parte importante en la definición de identidades sociales entre dos o más grupos en una comunidad.

Las unidades domésticas o grupos de parentesco pueden preparar alimentos a gran escala para captar mano de obra necesaria para plantar o cosechar (Meyerson 1990). Los movimientos de comunidades son asociados, muchas veces, con comidas comunales e intercambios de diferentes tipos. Esos eventos son auspiciados por líderes comunales y son realizados para construir o realizar mantenimiento de importantes componentes de la infraestructura de la economía colectiva de un grupo, tales como canales (Isbell 1978). Los Estados pueden financiar grandes proyectos de trabajo a largo plazo a través de la provisión de comida a los corvée (mit'a) trabajadores (Cieza de León 1959 [1553]). Es cuestionable si todas esas actividades pueden ser ubicadas en la misma categoría. ¿Sería posible que dichas comidas promovieran lazos de grupo a través de una experiencia compartida o sería más característico de alimentos entregados y consumidos en una atmósfera diferente? El contexto de la comida, cómo fue elaborada y cómo fue consumida debe ser considerado para entender cómo las "fiestas" se relacionaban con la economía política.

Los contextos de los eventos de comida o "áreas de fiestas" necesariamente requieren dos componentes: un área de producción y un área de consumo. Las evidencias de fiestas Wari han sido identificadas principalmente a través de la presencia de vajilla fragmentada en pisos y basurales (Brewster-Wray 1989; Cook 1987, 2001; Isbell et al. 1991; Ochatoma y Cabrera 2002). En este artículo describiré las diferentes manifestaciones de fiestas descubiertas en las excavaciones de contextos asociados al periodo Wari, cuenca alta de Moquegua, sur del Perú. Describiré la calidad de los alimentos, cómo fueron elaborados y el contexto de cada fiesta, para determinar cómo dichos eventos de comida jugaron un rol en la política dominante Wari. Además, describiré las instalaciones empleadas para la preparación de las fiestas y así proporcionar detalles para el entendimiento de la naturaleza de las relaciones asociadas con la realización de cada evento en donde se compartían alimentos. Primero, sin embargo, haré una pequeña introducción a la política 
Wari y su establecimiento en el área de estudio de Moquegua.

\section{La Política Wari}

El Estado Wari inició su expansión un tiempo después de consolidar su región original central, localizada en el área de Ayacucho, sierra del Perú. Grupos vecinos fueron traídos bajo el control o influencia de dicha política y los restos materiales de esas diferentes estrategias varían de región en región. La expansión Wari se inició desde AD 550 hasta 1.000 (Moseley et al. 2005; Williams 2001). En su máxima expansión, esta política mantuvo

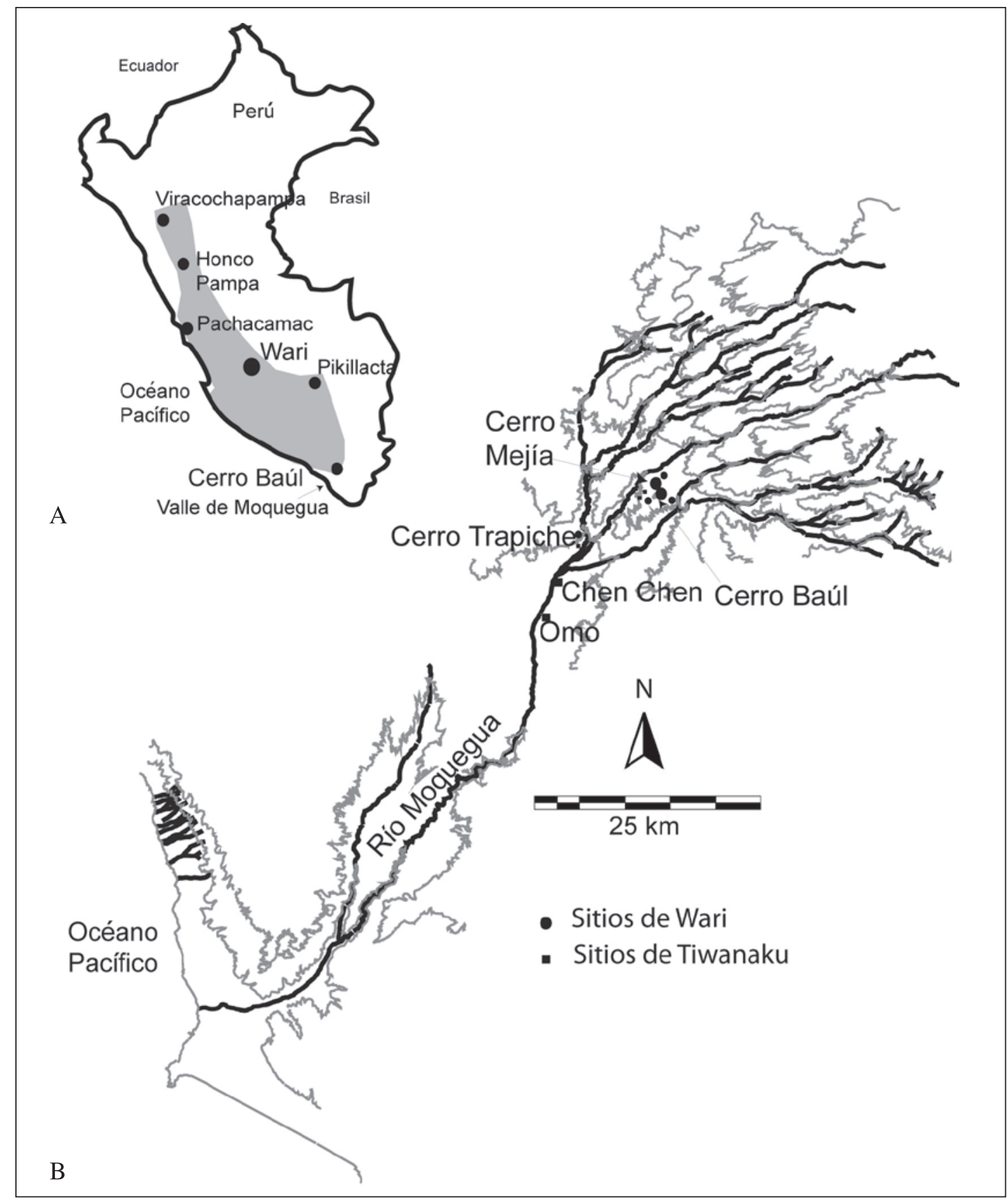

Figura 1. (A) Centros provinciales Wari en el Perú. (B) Sitios más importantes del valle de Moquegua en el Horizonte Medio. (A) Wari provincial centers in Peru. (B) Important sites in the Moquegua Valley during the Middle Horizon. 
dominio e influencia sobre un área que abarcó $1.200 \mathrm{~km}$ a través de la cordillera andina (Figura 1). En su centro, el sitio de Huari ${ }^{1}$ fue una extensa capital cosmopolita, cubriendo un área de al menos 4 kilómetros cuadrados y con un elaborado y monumental centro (Isbell et al. 1991). Wari fue una política con nivel de Estado, pero actualmente los arqueólogos tienen un escaso entendimiento de cómo exactamente esta política fue organizada y qué instituciones fueron cruciales para el mantenimiento del poder de los administradores del Estado (Nash y Williams 2005, 2009).

El Estado Wari colonizó la cuenca alta de Moquegua alrededor de los AD 600 (Williams 2001). Basados en investigaciones previas, se infiere que la colonia Wari fue administrada por oficiales viviendo en el centro provincial de Cerro Baúl, los cuales se conectaban a la capital en Ayacucho a través del movimiento de bienes (Moseley et al. 2005). La gente que habitaba en esta colonia no parece haber sido originaria del área de estudio de Moquegua, y posiblemente algunos fueron foráneos movilizados a esta zona por el imperio (Moseley et al. 1991; Nash 2002; 2009) ${ }^{2}$. Estos colonos, sin importar su región de origen, fueron miembros de la sociedad Wari y activos participantes en la política provincial. La colonia intrusiva fue probablemente planeada por los administradores del Estado Wari, porque existe mínima evidencia de ocupación durante el Formativo hallada en la cuenca alta de Moquegua (Owen y Goldstein 2001). Wari se movilizó a un paisaje semejante no ocupado. La motivación para la ocupación de Moquegua se mantiene incierta, sin embargo, la cercanía de esta frontera al área central (heartland) de Tiwanaku no puede ser ignorada, cualquiera que fuera el motivo, la inversión y el control de Wari en esta área fue extensa, a largo tiempo y bien desarrollada (Moseley et al. 2005), proveyendo una región importante para investigar las instituciones estatales Wari y para examinar el rol que las fiestas y las reuniones festivas jugaron en el desarrollo de la forma de gobierno andino.

Cerro Baúl, una sorprendente meseta, divide la cuenca alta de Torata y Tumilaca, tributarios del río Moquegua. La única ruta moderna que accede a la cima del centro provincial de Cerro Baúl está localizada en la cuenca del Torata, la más productiva de los tributarios del río Moquegua. Los Wari construyeron un considerable sistema de irrigación; más de $20 \mathrm{~km}$ de canal fueron cortados a través de un escarpado terreno y muchas de esas áreas están asociadas con la construcción de terrazas agrícolas. Esta región del valle alto, previamente no desarrollada, sólo pudo ser transformada por medio de grandes inversiones de trabajo, cuyas dimensiones sugieren que la colonia pudo haber sido autosuficiente (Williams 1997; Williams y Sims 1998). Cerro Mejía, el más grande asentamiento residencial, Cerro Petroglifo, Pampa del Arrastrado y varios conjuntos de restos residenciales en los flancos oeste y norte de Cerro Baúl también están ubicados en el valle de Torata. El Tenedor divisa el tributario de Tumilaca, y en el valle medio bajo de Moquegua hay un sitio Wari en el Cerro Trapiche (Figura 1). Basados en estimados agrícolas la población colonial pudo haber tenido unas 5.000 personas (Williams y Sims 1998), sin embargo, hasta el momento no hay evidencia de extensas ocupaciones durante dicho periodo. Algunos sitios necesitan ser fechados y no está claro cómo la población puede haber fluctuado, a través del tiempo, con los cambios organizacionales en la colonia (ver Nash y Williams 2005; Williams y Nash 2002). También hay indicios que los tipos de cerámica doméstica del Horizonte Medio y del periodo Intermedio Tardío son similares, por ello, el patrón de asentamientos necesita ser verificado mediante datación radiocarbónica.

El centro provincial de Cerro Baúl está localizado sobre la cima de una escarpada meseta. La mayor parte de la cima está cubierta por ruinas, que fueron alguna vez edificios administrativos, elaborados componentes residenciales, templos y monumentos ceremoniales. La arquitectura está aglutinada y es difícil categorizar la organización del sitio. En líneas generales, las construcciones monumentales y de alta calidad fueron construidas en la cima sobre superficies amplias y artificialmente aplanadas, y las residencias más modestas y edificios pequeños están localizados en terrazas que descienden hacia los abruptos bordes de la meseta. Lamentablemente, la severa erosión no permite un cálculo exacto del tamaño del sitio y de su población.

Los esfuerzos constructivos en Cerro Baúl y la ocupación del sitio reflejan una exorbitante cantidad de trabajo invertido. La fuente de agua más cercana está localizada a unos $600 \mathrm{~m}$ cuesta abajo (Feldman 1989). El principal material constructivo fue predominantemente obtenido de canteras ubicadas en el sitio, sin embargo, el mortero y el enlucido de los muros y pisos habrían requerido toneladas de arcilla y agua. La ocupación en Cerro Baúl representa el control de grandes cantidades de recursos, 
no sólo para su construcción, sino también para el simple sustento del día a día, ya que su localización demandó esfuerzos adicionales.

El asentamiento en Cerro Mejía es más modesto, sin embargo, su construcción también requirió una gran inversión de trabajo. La organización del sitio es más fácil de describir debido a que la arquitectura no es aglutinada sino dispersa sobre la cima y la ladera sur del cerro. La ocupación fue dividida por claros y notorios límites, grandes segmentos de muros rodean la cima del cerro donde los edificios más grandes estuvieron localizados. Una escalera monumental provee el acceso hacia ésta. En la ladera sur de Cerro Mejía, terrazas dispersas de ocupación son distribuidas a lo largo de $600 \mathrm{~m}$ y sobre una sección del canal Wari. Cerca de 200 terrazas organizadas individualmente y en grupos permanecen reconocibles, y forman al menos 80 residencias diferentes. Muchas de ellas disponían de superficies planas para construir modestas residencias, por lo que el largo, ancho y altura es altamente variable. El plano de las casas presenta una gran diversidad en su organización y los correspondientes cuartos de una residencia son ovales, rectangulares o ambos. Las laderas están divididas en seis barrios por grandes muros, con más de un metro de ancho en algunos casos. Cada sector residencial contiene ocho o más estructuras de casas de diferentes tamaños (Figura 2). Basados en los recientes fechados radiocarbónicos el sitio de Cerro Mejía fue abandonado posterior al año AD 800. Todas las casas excavadas parecen haber sido ocupadas durante el mismo periodo temprano del Horizonte Medio (Nash 2002; ver Figura 3).

La colonia Wari en Moquegua es original porque constituye la única región conocida, hasta el momento, donde se han reportado tan próximos a asentamientos de sus contemporáneos los Tiwanaku. La ubicación de Cerro Trapiche sugiere que éste pudo haber tenido algún rol en la interacción con los colonos Tiwanaku, que ocupaban la zona del valle medio. A pesar de ello, Cerro Baúl fue probablemente un lugar formal para las relaciones con esta vecina peer política, haciendo que la naturaleza de las interacciones políticas entre comensales en Cerro Baúl fuera más significativa (Moseley et al. 2005).

\section{Comidas y sus Contextos}

La muestra descrita corresponde a los contextos en Cerro Baúl y el asentamiento adyacente de Cerro Mejía. Los materiales arqueológicos de estos contextos son de dos tipos: algunas áreas parecen exhibir simplemente de facto refuse (Lightfoot 1993; Schiffer 1987; Stevenson 1982) y otras los restos de eventos intencionales de cierre (Cook 2001). Vasijas y herramientas fueron rotas intencionalmente

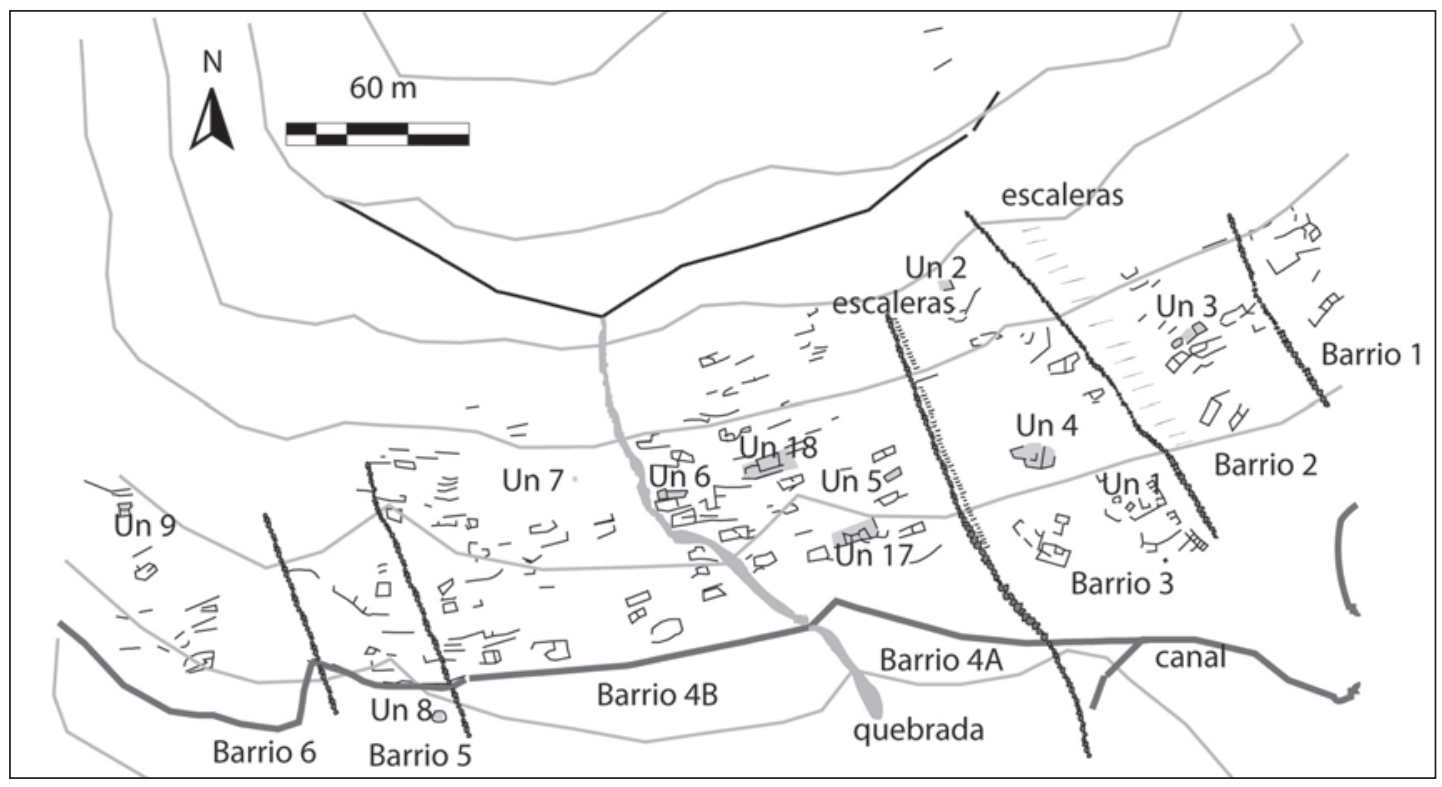

Figura 2. Ladera sur del Cerro Mejía, dividida por gruesos muros generando barrios.

The southern slope of Cerro Mejía, divided by thick walls into neighborhoods. 
OxCal v4.1.7 Bronk Ramsey (2010): r:5 SHCal04 southern hemisphere atmospheric curve (McCormac et al. 2004)

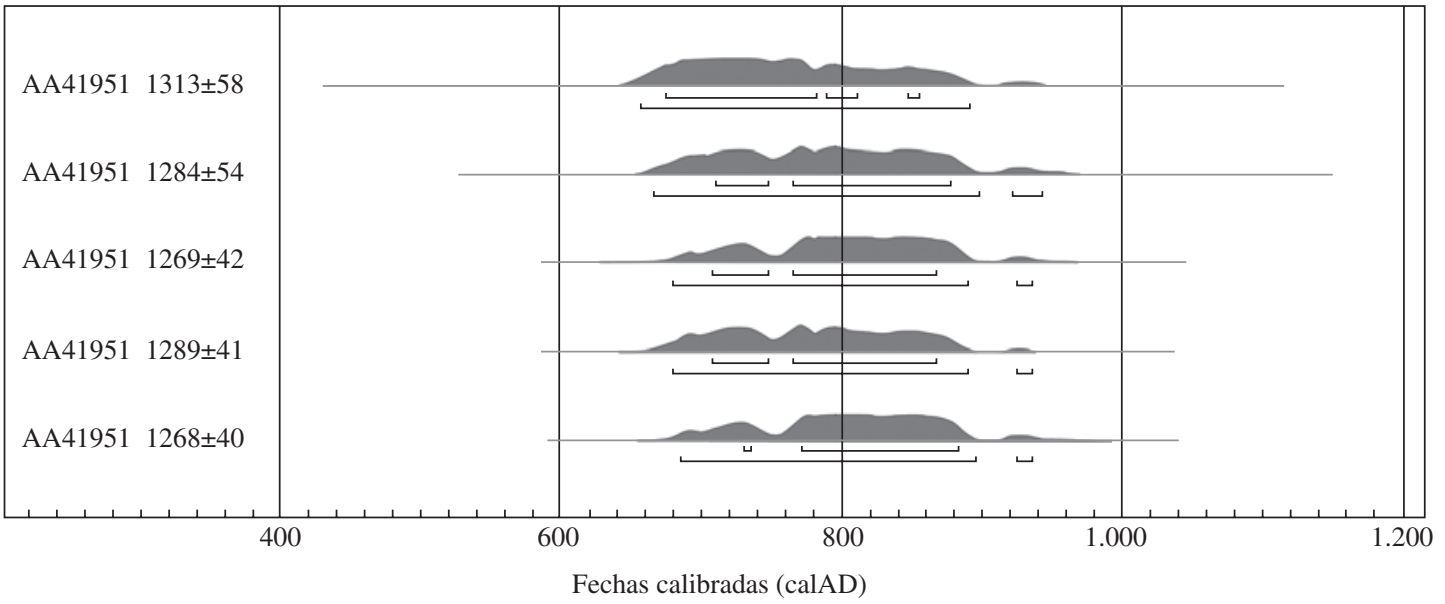

Figura 3. Fechas calibradas del Cerro Mejía usando Oxcal. Casas comunes en las laderas incluyen la Unidad 3 (AA41951) y la Unidad 5 (AA41954); el gran agrupamiento de casas en la cima que no presentan la forma de grupo de patio: Unidad 118 (AA41955); y las residencias de grupo de patio Wari en la cima de Cerro Mejía: Unidad 136 (AA41956) y Unidad 145 (AA41952).

Calibrated dates from Cerro Mejía using Oxcal. Common houses on the slopes include Unit 3 (AA41951) and Unit 5 (AA41954); the large cluster of houses of the summit that does not exhibit the patio group form: Unit 118 (AA41955); and the Wari patio group residences on the summit of Cerro Mejía: Unit 136 (AA41956) and Unit 145 (AA41952).

y halladas asociadas con evidencias de fiestas. La naturaleza de los eventos intencionales de cierre se relaciona con el estatus de los ocupantes de la casa o de la importancia del área en ceremonias del Estado. Es posible que el abandono de las estructuras en la sociedad Wari fuera comúnmente asociado con rituales que requirieron algún tipo de fiesta. Los eventos intencionales de cierre pudieron relacionarse con la muerte de un miembro de la familia o el abandono de la casa por otra razón. Tales eventos fueron, posiblemente, personales. Sin embargo, la muerte de una persona poderosa es un momento político importante cuando las alianzas deben ser reforzadas, la competencia puede ser violenta y el poder está para ser tomado. Fiestas fúnebres, como otras reuniones rituales, son importantes eventos políticos que pueden revelar aspectos de la economía política (Underhill 2002). Con un cuidadoso análisis se puede determinar si las fiestas fueron importantes eventos durante la vida de una estructura o si fue sólo después de su abandono.

\section{Comidas diarias en las casas}

Una típica casa en Cerro Mejía consistía en un simple cuarto cerrado con un patio amurallado adjunto o de dos o más cuartos cerrados que compartían el mismo patio. Las estructuras residenciales en las laderas aterrazadas presentan restos de animales dispersos que, típicamente, consistían en pedazos de huesos fragmentados sobre el piso de la casa. No hubo evidencias de cuy doméstico (Guinea pig) (deFrance 2004). Los cuartos cerrados estaban asociados con la preparación de alimentos y los fogones eran pequeños, sin una estructura formal (Nash 2002), no hay evidencia de almacenaje. Es posible que los productos fueran guardados en las vigas del techo, no se observan contenedores o espacios vacíos en los pisos donde poner sacos o vasijas.

Cada cuarto cerrado tenía su propio fogón, incluso las unidades domésticas multifamiliares no presentan una cocina excesivamente amplia que pueda sugerir que las comidas hayan sido preparadas para un número mayor de personas que vivían en la estructura (Figura 4). Los fogones fueron pequeños y oscilan entre $3.200 \mathrm{~cm}^{2}$ a $4.000 \mathrm{~cm}^{2}$. Los cuartos cerrados fueron pequeños espacios cuadrados que habrían restringido a una o dos personas de participar activamente en el fogón (Tabla 1).

Todas las casas tenían vasijas que pudieron ser usadas para el consumo de una comida especial, o las más grandes tenían mayor número de fragmentos de dichas vasijas (Tabla 2). Evidencias de consumo fueron localizadas predominantemente en el patio de muchas de las casas. El agrupamiento de estos 


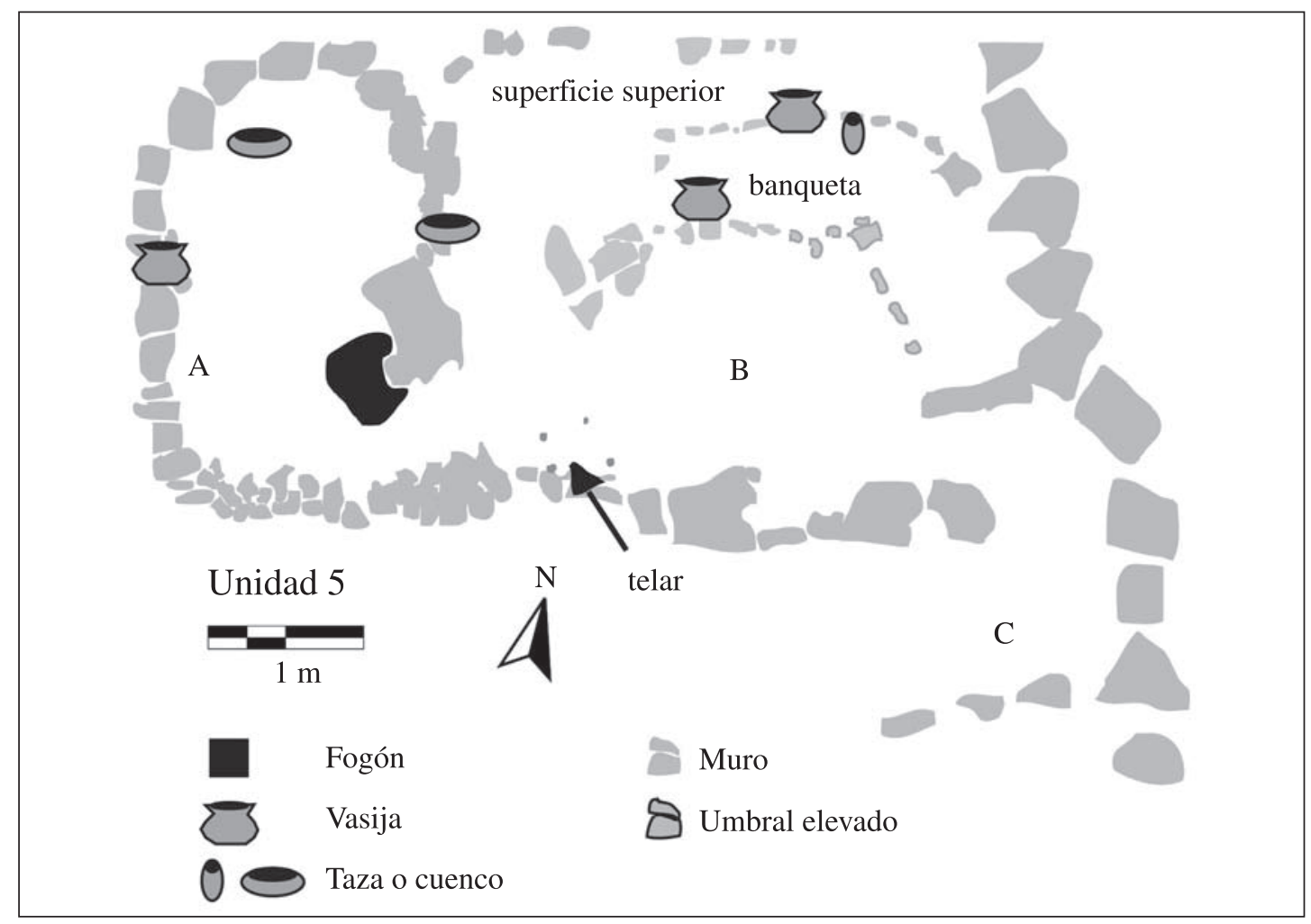

Figura 4. Planta de la Unidad 5 en Cerro Mejía.

Plan of Unit 5 on Cerro Mejía.

Tabla 1. Tamaño de los fogones.

Hearth sizes.

\begin{tabular}{|c|c|c|c|c|}
\hline Sitio & Tipo de Residencia & Contexto & Cantidad de fogones & Area total de fogones \\
\hline C. Mejía & Casa típica & $\mathrm{U} 3, \operatorname{Rec} \mathrm{B}$ & 1 & $4.000 \mathrm{~cm}^{2}$ \\
\hline C. Mejía & Casa típica & $\mathrm{U} 3, \operatorname{Rec} C$ & 1 & $3.200 \mathrm{~cm}^{2}$ \\
\hline C. Mejía & Casa típica & U 5, Rec A & 1 & $3.600 \mathrm{~cm}^{2}$ \\
\hline C. Mejía & Casa típica & $\mathrm{U} 6, \operatorname{Rec} \mathrm{A}$ & 1 & $3.600 \mathrm{~cm}^{2}$ \\
\hline C. Mejía & Casa del líder del barrio & $\mathrm{U} 4, \operatorname{Rec} \mathrm{A}$ & 1 & $7.400 \mathrm{~cm}^{2}$ \\
\hline C. Mejía & Casa típica en la cima & $\begin{array}{l}\text { U 118, Rec B } \\
\text { (Casa 1) }\end{array}$ & 1 & $6.600 \mathrm{~cm}^{2}$ \\
\hline C. Mejía & Casa típica en la cima & $\begin{array}{l}\text { U 118, Rec E } \\
\text { (Casa 2) }\end{array}$ & 1 & $6.600 \mathrm{~cm}^{2}$ \\
\hline C. Mejía & Casa típica en la cima & $\begin{array}{l}\text { U 118, Rec F } \\
\text { (Casa 3) }\end{array}$ & 2 & $8.800 \mathrm{~cm}^{2}$ \\
\hline C. Mejía & Casa típica en la cima & $\begin{array}{l}\text { U 118, Rec I } \\
\text { (Casa 4) }\end{array}$ & 1 & $1.600 \mathrm{~cm}^{2}$ \\
\hline C. Mejía & Grupo de Patio & U $145, \operatorname{Rec} A$ & 1 & $7.200 \mathrm{~cm}^{2}$ \\
\hline C. Mejía & Grupo de Patio & U 145, Rec B & 1 & $14.000 \mathrm{~cm}^{2}$ \\
\hline C. Mejía & Grupo de Patio & $\begin{array}{c}\text { U 145, Rec C } \\
\text { Fogones normales }\end{array}$ & 3 & $37.500 \mathrm{~cm}^{2}$ \\
\hline C. Mejía & Grupo de Patio & $\begin{array}{c}\text { U } 145, \text { Rec C } \\
\text { Fogones para preparar } \\
\text { chicha }\end{array}$ & 4 & $8.600 \mathrm{~cm}^{2}$ \\
\hline C. Baúl & Dentro del Palacio & U 41, Rec B & 1 & $6.950 \mathrm{~cm}^{2}$ \\
\hline
\end{tabular}


Tabla 2. Vasijas de servicio por residencia. Serving vessels by residence.

\begin{tabular}{cccccc}
\hline Residencia & Tipo de residencia & $\begin{array}{c}\text { Cantidad de vasijas } \\
\text { de servicio }\end{array}$ & Total cerámica & Área de residencia* & $\begin{array}{c}\text { Porcentaje de } \\
\text { vasijas de servicio }\end{array}$ \\
\hline Un 3 & Casa típica & 5 & 824 & $33 \mathrm{~m}^{2}$ & $0,6 \%$ \\
Un 5 & Casa típica & 15 & 276 & $11,6 \mathrm{~m}^{2}$ & $5 \%$ \\
Un 6 & Casa típica & 7 & 160 & $12,65 \mathrm{~m}^{2}$ & $4 \%$ \\
Un 4 & Casa del líder del barrio & 133 & 1006 & $54 \mathrm{~m}^{2}$ & $13 \%$ \\
Un 145 & Grupo de Patio & 108 & 963 & $115 \mathrm{~m}^{2}$ & $11 \%$ \\
\hline
\end{tabular}

* Incluye el área de la residencia que fue excavada hasta la superficie del piso más alto, no incluye áreas que permanecen sin excavar.

fragmentos sugiere que en algunas residencias la ruptura de las vasijas o eventos intencionales de cierre pudo haber coincidido con el abandono de la estructura. En muchas de las casas de la muestra excavada no se ha hallado ninguna evidencia de fiesta. Si una comida simbólica fue asociada con el abandono de cada casa no hay indicios para sugerir que otras personas además de los que vivían allí asistieron a dicho evento (aproximadamente, cuatro a cinco personas por fogón ver Nash 2002, 2009), tampoco hay evidencias de haberse preparado o servido ningún tipo de alimento especial.

\section{Una gran comida en la casa del jefe del barrio}

La Unidad 4, ubicada en las laderas de Cerro Mejía, presenta características que sugieren que las fiestas probablemente coincidieron con el abandono de la estructura, e incluyeron a miembros que no pertenecían a la unidad doméstica

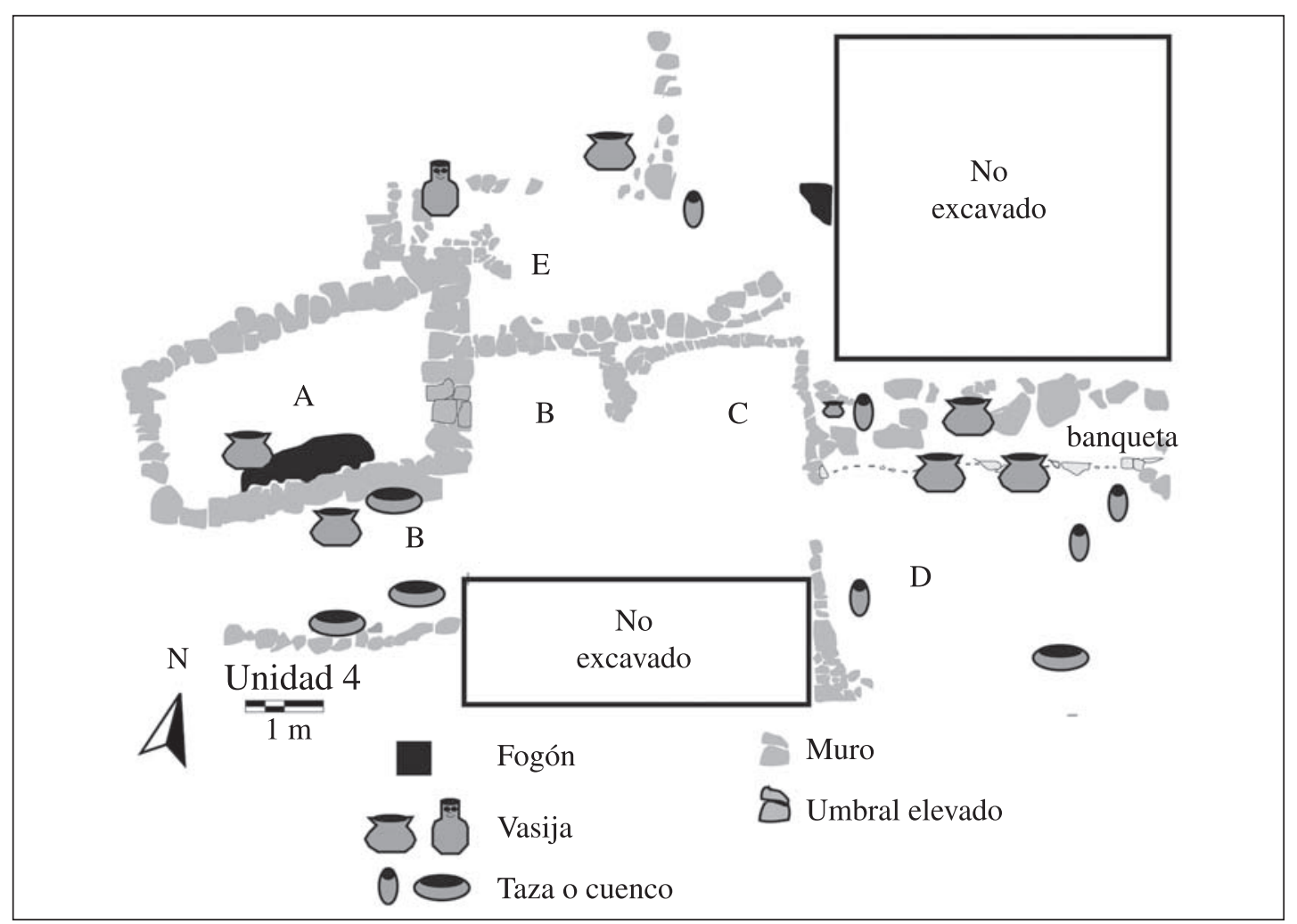

Figura 5. Planta de la Unidad 4 en Cerro Mejía.

Plan of Unit 4 on Cerro Mejía. 
(Figura 5). Esta idea está sustentada por el tamaño del área de vivienda en relación a la cantidad de los menajes de servicio (Tabla 2), el potencial de la cocina representado por el fogón de gran tamaño (Tabla 1) y la relativa limpieza del cuarto en la entrada de la residencia, que pudo ser agregado a la estructura para recibir visitas. La Unidad 4 tiene un cuarto rectangular cerrado con un fogón, excepcionalmente grande, con más de $7.400 \mathrm{~cm}^{2}$. El fogón estuvo asociado con una inusual cantidad de huesos de camélidos quemados, casi un kilogramo (963,6 g), que es más de cuatro veces la cantidad en comparación con cualquier otra casa en las laderas aterrazadas (Nash 2002). Debido a que no hay evidencia de almacenamiento es posible que tales cantidades de carne pudieron ser provistas por un auspiciador.

Una cocina más grande habría permitido más personas para atender, muchas vasijas de cocción en un fogón largo y ovoide. Este agrandamiento del área de preparación de alimentos y los restos de una considerable cantidad de comida están dentro de una residencia que también tiene un espacio extra, con una forma que podría llamarse hall de entrada. Esta estructura fue remodelada en algún momento durante su ocupación para añadir este espacio de reunión y un pequeño nicho con un muro posterior redondeado. Estas áreas están relativamente limpias en comparación con el patio y el cuarto cerrado, que presentaban típicos patrones de actividad doméstica. Por lo tanto, en el caso de la Unidad 4 hubo un área más grande de preparación de comida y el cuarto cerrado también fue más grande. La comida, aparentemente, no fue rica o exótica, pero, en términos de proteínas, pudo haber estado más allá de los niveles normales. Los menajes de servicio fueron más numerosos en esta residencia y demostraron una variedad de formas y pastas, quizás porque esta unidad doméstica estuvo envuelta en intercambio o mantuvo relaciones recíprocas con otras dentro o más allá de la comunidad. Mucho del menaje de servicio fue recuperado de un área especial añadida a la casa para facilitar las interacciones con los miembros de la comunidad, y quizás, para entablar interacciones políticas entre comensales. Aunque relativamente pequeña, parece que esta residencia tuvo acceso a recursos alimentarios más distantes a sus vecinos y un cuarto destinado para albergar reuniones. Muchas casas de similar tamaño no tenían tales características. Debido a que la gran cocina y el hall de entrada fueron agregados por medio de remodelaciones, es posible que el estatus del líder del barrio fuera logrado en vez de heredado, lo cual puede tener importantes implicancias para las interacciones con el Estado.

\section{Una comida festiva en la casa del líder del poblado}

En la cima de Cerro Mejía las agrupaciones residenciales son mucho más grandes, incluyendo extensos patios y numerosos cuartos cerrados. En varios ejemplos, dos o más casas compartían muros y salidas como grupos residenciales. Debido a su tamaño, sólo dos estructuras fueron excavadas en la cima. Por consiguiente, la muestra es pequeña, sin embargo, las diferencias son bien marcadas entre ambas estructuras. Los restos asociados presentan amplias diferencias que probablemente representan una clara desigualdad de estatus entre los ocupantes. Ésta es apoyada por la elaboración de muros de piedra, pero no por el tamaño de las estructuras. La Unidad 145 es una residencia que presenta cánones constructivos de la arquitectura Wari (Figura 6), imitando los patrones de la capital Wari, de los centros provinciales a lo largo de la sierra y de Cerro Baúl, el establecimiento local (Cook y Glowacki 2003; Isbell 1991; McEwan 1991; Nash y Williams 2005; Schreiber 1992). La Unidad 145 es una de las dos estructuras residenciales ubicadas centralmente en Cerro Mejía que usan esta forma, a la cual referiré como "grupo patio Wari".

La Unidad 145 consiste en una agrupación de cuatro cuartos (A, B, C y D) que, parcialmente, encierra a un patio central de forma trapezoidal (E, Figura 6). Este grupo patio Wari estaba asociado a una gran plaza que aún no ha sido excavada y a la que se accedía a través de un estrecho corredor (F). Durante las excavaciones la cantidad del colapso de los muros de piedra fue consistente con cuartos de un solo piso. Los accesos y umbrales fueron construidos con piedras labradas, pero el otro trabajo consistió en piedras de campo irregulares cuidadosamente seleccionadas para construir muros con paramentos relativamente planos. Esta construcción es más modesta que la de Cerro Baúl, pero de mejor calidad que las residencias en las laderas de Cerro Mejía y de muchas otras residencias en la cima. Dos de los cuartos tienen cistas de almacenaje en el piso (A y D); adicionalmente, en ambos cuartos A y B hay áreas provistas de artefactos que pudieron haber sido usados para 


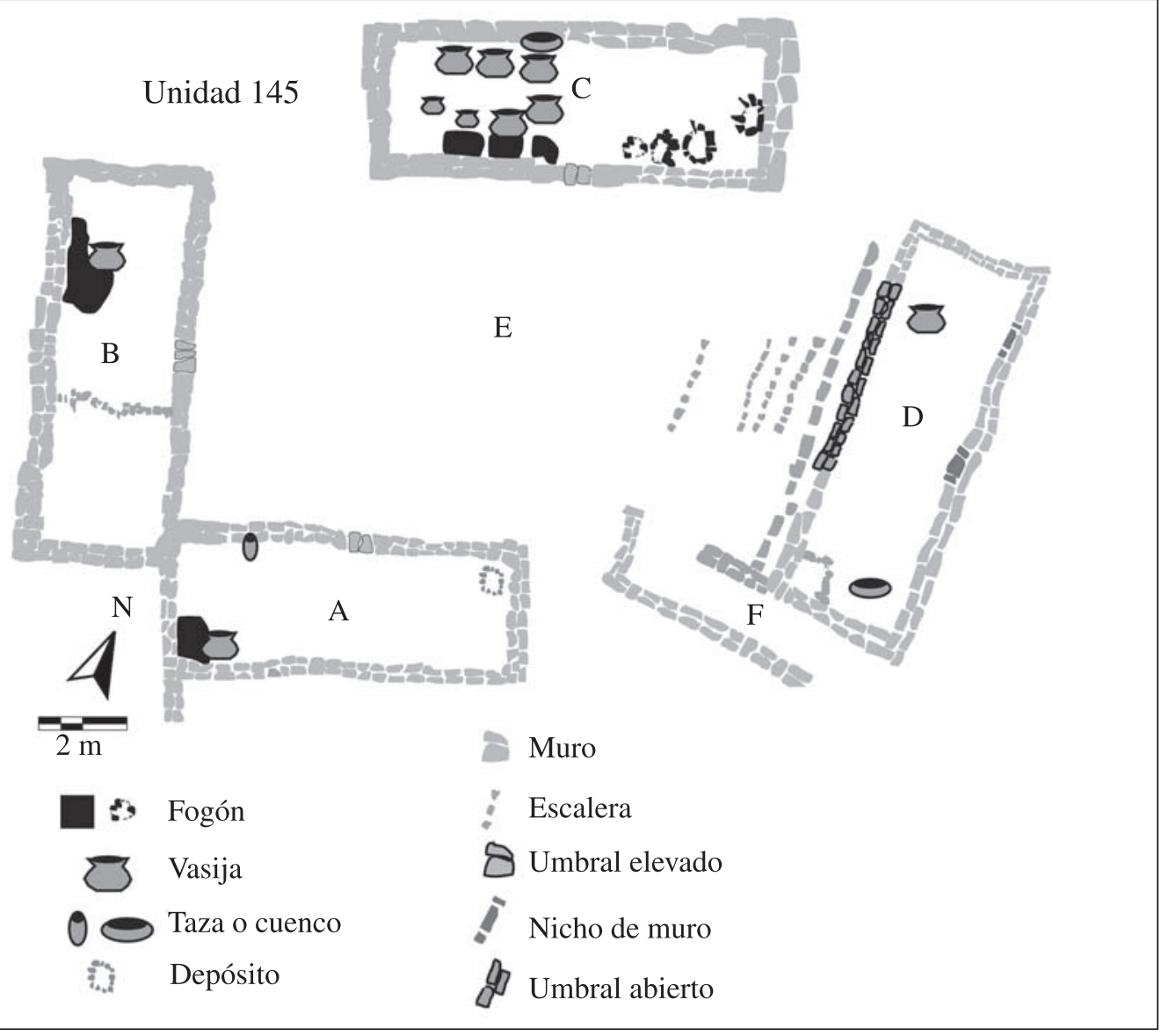

Figura 6. Planta de la Unidad 145 en Cerro Mejía.

Plan of Unit 145 on Cerro Mejía.

el almacenaje en sacos o en grandes vasijas. Los sacos o vasijas pudieron limitar el uso de estas áreas, resultando en depósitos de materiales en el piso. Si éste fuera el caso, la Unidad 145 pudo almacenar excedentes de alimentos para realizar celebraciones, quizás regularmente.

El cuarto C, en la Unidad 145, es un contexto especializado en la intensificación de la preparación de comida. Contenía siete fogones de dos tipos y numerosos restos de vasijas de cocción y de almacenaje, también dos kilos y medio $(2508,1 \mathrm{~g})$ de huesos de camélido carbonizados, cinco veces más que todas las áreas de cocción de las otras residencias ubicadas en la cima del Cerro Mejía. Fogones de piedra alineados, cuatro de ellos ubicados al este de la puerta, se presume que pudieron haber sido usados para hervir. A diferencia de la mayoría de los fogones en Cerro Mejía, dichos fogones tienen bordes de piedra para soportar vasijas de base cónica que estuvieron llenos de briquetas de madera, un combustible no recuperado en otro contexto. Ninguna otra estructura de vivienda en Cerro Mejía presentó fogones de tal naturaleza que pudieran haber sido utilizados para preparar chicha. Podría ser que la producción de ésta, una bebida fermentada, fuera reservada como un privilegio para la élite. Los tres fogones sin ninguna estructura (característico de muchos de los fogones en el sitio) estuvieron llenos de huesos calcinados de camélidos. Esta área tuvo una mínima producción de desechos, sugiriendo que gran parte de la preparación preliminar tuvo lugar en otra parte (Nash 2002).

Los Cuartos A y B presentan cualidades de típicas unidades domésticas, inclusive éstos son increíblemente limpios en comparación con los desechos domésticos de otras estructuras residenciales. Como sólo hay dos unidades familiares al interior de la estructura y cada una de ellas tiene su propia 
área de preparación de comida, podría parecer que las áreas en el Cuarto C son para la preparación de alimentos a ser compartidos con más que sólo miembros de la unidad doméstica. La gran área de preparación fue ubicada en un cuarto separado del área de cocina y de vivienda de los ocupantes de la residencia. Esto tiene implicancias para las relaciones sociales entre aquellos preparando activamente la comida y la gente que residía en los Cuartos A y B. Es posible que el personal que no pertenecía a la unidad doméstica, muy probablemente mujeres -relacionadas a administradores subordinados-, contribuyeron con su labor a la preparación de eventos donde se compartían alimentos a gran escala. Las mujeres que vivían en la Unidad 145 también pudieron haber contribuido con su trabajo o pudieron haber tomado un rol de supervisión. Basados

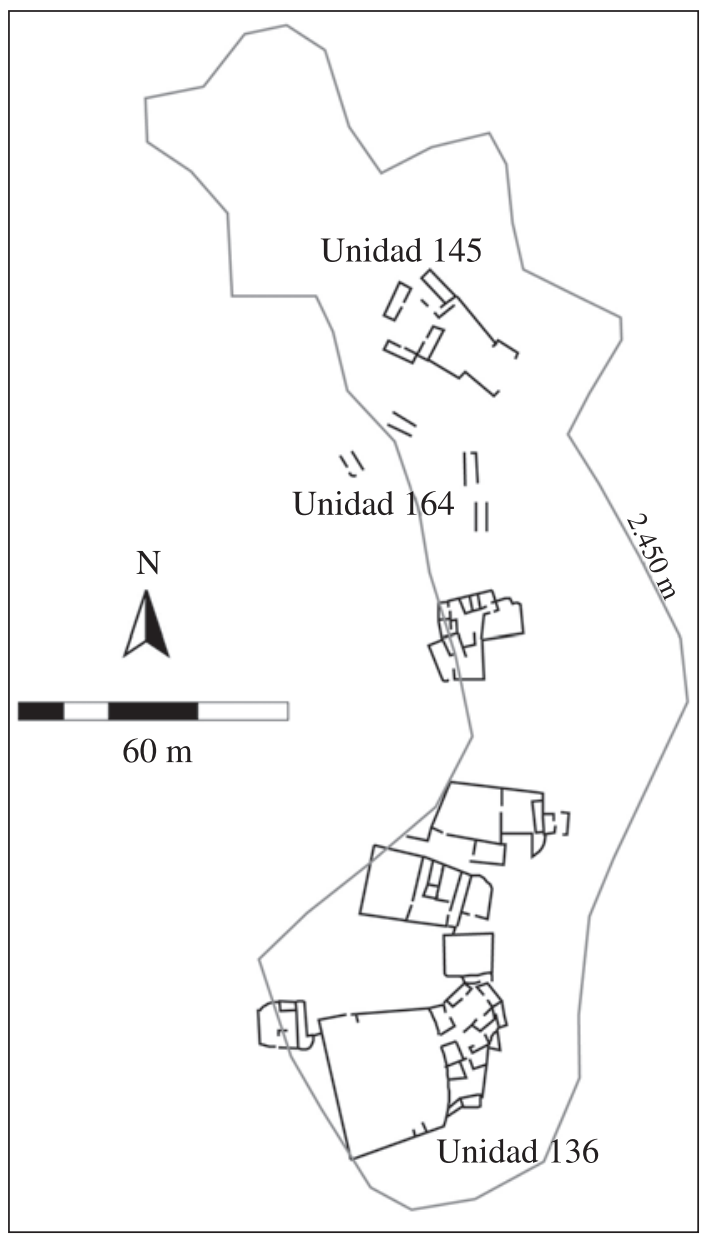

Figura 7. Mapa con los edificios ubicados en la zona central de la cumbre del Cerro Mejía.

Map of the buildings located in the central area of the summit on Cerro Mejía. en la evidencia deposicional parece, también, que cierta preparación preliminar de alimentos puede haber sido realizada en otras áreas antes de haber sido cocinadas en el Cuarto C.

El Cuarto D de la Unidad 145 y el patio central proporcionan un espacio para acoger una audiencia con subordinados. Es elevado, tiene un piso cubierto con lajas y una amplia apertura hacia el patio. Su muro de contención exterior está alineado con una banqueta. Tres escaleras conducen hacia una plataforma elevada sobre el nivel del piso del patio central. Durante su uso, las características arquitectónicas de esta estructura facilitaron la definición de la interacción y el estatus relativo de los tres grupos de individuos: los ubicados en el patio, los de un nivel sobre la plataforma baja y aquellos, incluso, en posiciones más elevadas presidiendo los eventos desde el cuarto elevado. Aparentemente, esta estructura residencial fue diseñada para acomodar interacciones sociopolíticas, así como para preparar y proveer fiestas a los visitantes, subordinados y quizás grandes grupos de la colonia y asentamientos vecinos en el complejo adyacente a la plataforma central (Nash 2002).

Hay cuatro plataformas principales localizadas centralmente en la cima de Cerro Mejía, dos hacia el este y dos pequeñas al norte de un gran espacio público, la Unidad 164 (Figura 7). La plaza, de $65 \mathrm{~m}$ por $75 \mathrm{~m}$, puede haber sido el espacio para reuniones a gran escala. En la actualidad la única evidencia que sugiere que este espacio haya estado relacionado a fiestas es su cercanía al área de preparación de alimentos en gran escala en la Unidad 145 y aquellas en la Unidad 136, ambas son idénticas en escala y localizadas en un patio grupal formal Wari (Figura 7). Futuras investigaciones en Cerro Mejía serán designadas para preparar y delinear la actividad o actividades que se desarrollaron en este significante espacio público y en las más elaboradas estructuras residenciales de élite, Unidad 136.

\section{Una gran fiesta en un palacio provincial de Cerro Baúl}

Hasta la fecha, las excavaciones en el centro provincial sugieren que Cerro Baúl mantuvo fuertes lazos con la capital ubicada en Ayacucho y tuvo acceso a productos que provenían de todo el imperio, e incluso, más allá (Moseley et al. 2005). En Cerro Baúl, la élite de administradores que ocupó 


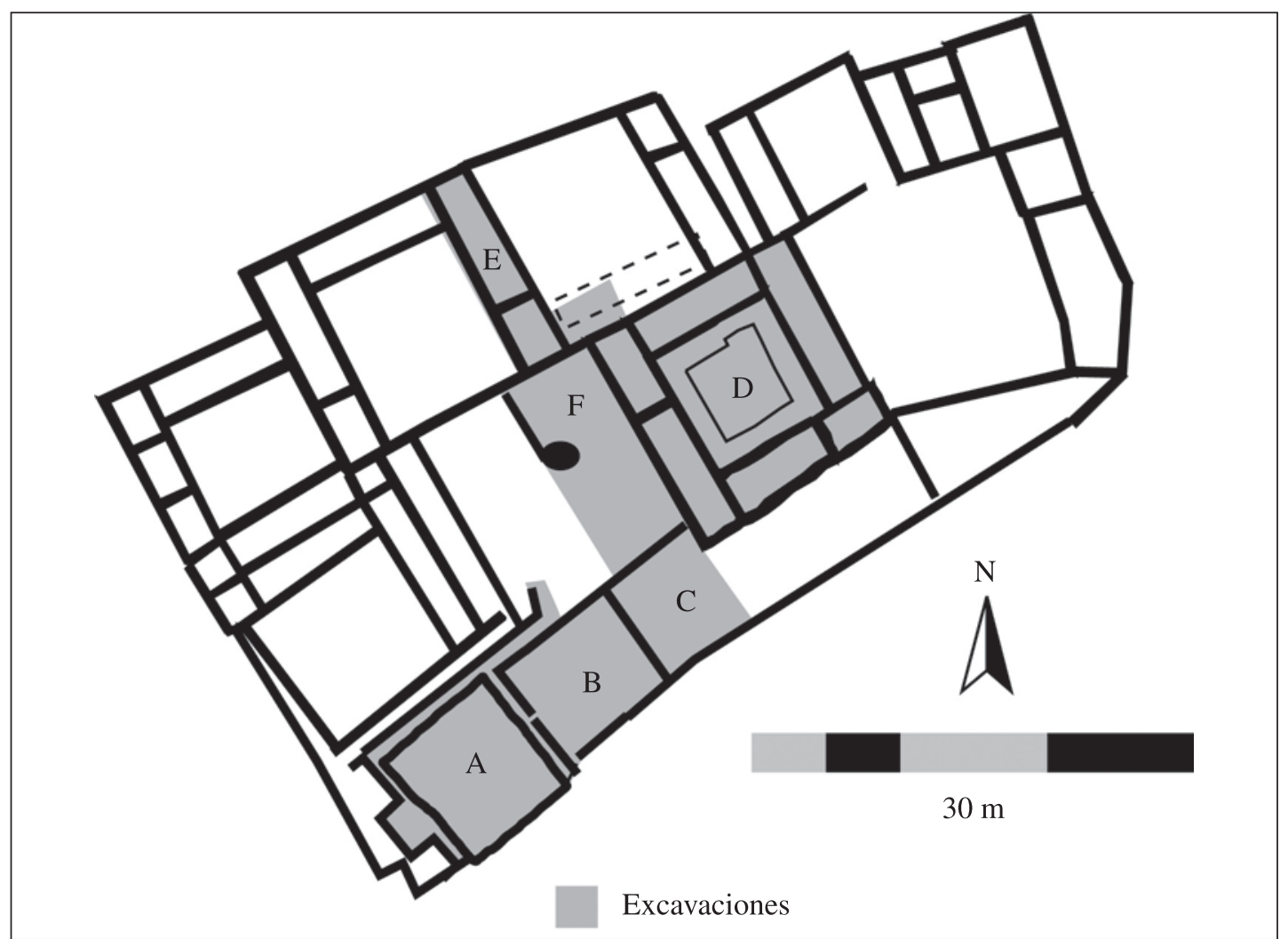

Figura 8. Mapa del palacio del Cerro Baúl en el Sector A. Los espacios excavados incluyen: (A) un hall de entrada (Unidad 25); (B) un taller de cerámica (Unidad 40A); (C) un jardín (Unidad 40C); (D) una residencia de grupo de patio (Unidad 9); (E) un pequeño aterrazamiento para la preparación de alimentos (Unidades 41A, 41B y 41C); y (F) un patio (Unidad 41E).

Map of the palace in Sector A of Cerro Baúl. The excavated areas include: (A) an entrance hall (Unit 25); (B) a ceramic workshop (Unit 40A); (C) a garden (Unit 40C); (D) a patio group residence (Unit 9); (E) a terraced area for small scale food preparation (Units 41A, 41B, and 41C); and (F) a patio (Unit 41E).

el gran palacio de $2.060 \mathrm{~m}^{2}$ pudo haber provenido del área central Wari (Figura 8). Ingresando por el oeste hay un atrio de forma indeterminada desde el cual los visitantes podían acceder al gran salón de recepción (Unidad 25). Este patio tiene banquetas en sus cuatro muros y una gran área de descanso hacia el muro oeste. El patio vecino hacia el este es un taller de cerámica donde las materias primas fueron procesadas y almacenadas y donde pudieron prepararse vasijas (Unidad 40A). Una gran plaza hacia el norte (Unidad 41E) también presenta evidencia de producción de cerámica (molienda de temperantes y el almacenamiento de pigmentos para engobe), así como otras actividades productivas (textilería y trabajo en piedra). Otros espacios excavados incluyen un irregular jardín con árboles (Unidad 40C), una pequeña área de cocina (Unidad 41B) y un grupo patio Wari (Unidad 9).
La Unidad 9, una residencia grupo patio Wari, está localizada en la porción este del centro monumental. Consiste de un espacio amurallado casi cuadrado, con cinco cuartos rectangulares en los tres lados de un patio abierto y con una plataforma elevada a lo largo del lado este (Figura 9). Esta residencia de élite tiene piso de piedra; otras características elaboradas sugieren que fue, alguna vez, una fabulosa residencia. El patio central fue rellenado con los restos de una gran fiesta, representado por más de 60 vasijas rotas y una diversidad de restos de comida, incluyendo huesos provenientes de finos cortes de carne de camélido, varias especies de pescado, camarón de río (deFrance 2004) y maíz. Las banquetas a lo largo de los cuatro lados del patio proporcionaban asiento para las reuniones y las relaciones sociopolíticas. Sorprendentemente, la Unidad 9 no tiene espacios adecuados para la preparación de alimentos a esta escala; sin embargo, 


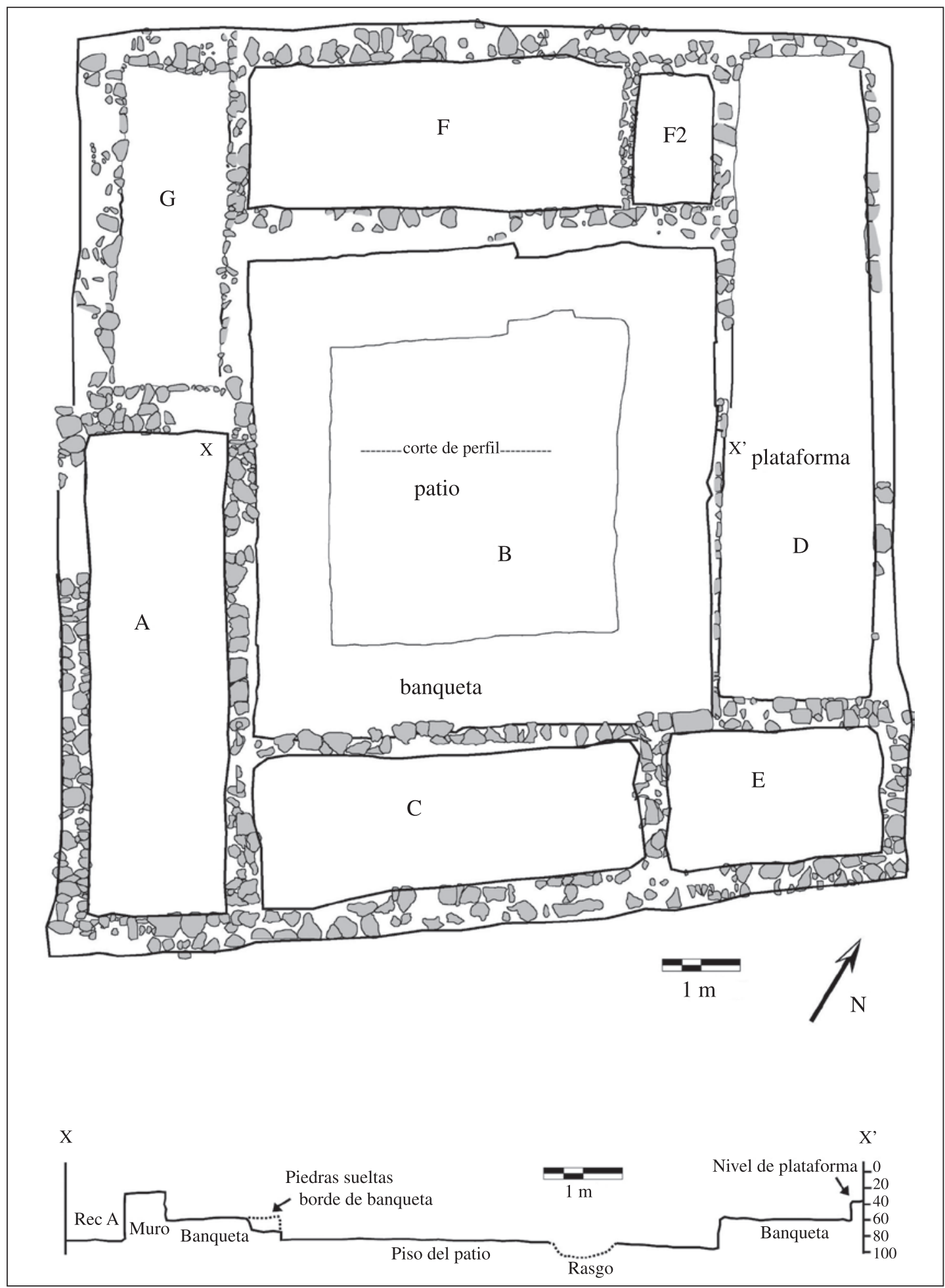

Figura 9. Planta de la Unidad 9 del Cerro Baúl. Los cuartos A, C, F y G contienen típicos restos domésticos, B es el patio central, $\mathrm{D}$ es una plataforma elevada y E parece haber sido reservada para actividades rituales.

Plan of Unit 9 on Cerro Baúl. Rooms A, C, F, and $G$ contain typical domestic remains, $B$ is the central patio, $D$ is an elevated platform and $E$ seems to have been reserved for ritual activities. 
una gran vasija de almacenamiento hallada en 9F y $41 \mathrm{C}$ ha sido interpretada como otra área para almacenamiento. Semejante a la Unidad 145 en Cerro Mejía, la estructura estuvo relativamente limpia, carente de artefactos, y con evidencia de ciertas tareas domésticas similares a las pequeñas residencias en ese sitio.

La Unidad 7, localizada fuera del palacio, fue una terraza abierta en dos niveles, con un área especial para la preparación de comidas y almacenaje de frutos de molle (Figura 10). El molle fue almacenado en un gran hoyo y su presencia sugiere que la producción de chicha tuvo lugar en los alrededores. El molle puede ser agregado a la chicha de maíz o ser fermentado y usado para preparar chicha de molle ${ }^{3}$. Manos de moler, porotos y restos de animales sugieren que esta zona también fue usada para preparar alimentos. La densidad de manos de moler y la ausencia de actividades típicas de una unidad doméstica, más allá de la preparación de comida, indican que fue un área especializada en vez de un contexto residencial.

Asimismo, la alta calidad de alimentos disponibles para los residentes de élite en Cerro Baúl sugiere que otras personas asociadas a estas unidades domésticas prepararon y potencialmente sirvieron chicha y alimentos a ellos y a sus invitados en la Unidad 9. Las evidencias de fiestas recuperadas en esta unidad parecen haber sido parte de un evento intencional de cierre, probablemente un funeral. Numerosas vasijas de cerámica fueron intencionalmente rotas en el piso y agrupadas alrededor de una tumba en el patio ${ }^{4}$. Por sí sola esta evidencia no podría soportar la presunción que las fiestas fueron un evento repetido con regularidad en esta área residencial. Las características de la Unidad 9, tales como la elevada plataforma hacia el este, sugieren que reuniones de algún tipo, probablemente con interacciones asimétricas, tuvieron lugar en la estructura y que las banquetas proporcionaron un lugar para sentarse y sostener amplias discusiones, realizar interacciones políticas y promover relaciones comensales (Figura 9).

De manera similar a la Unidad 4 en Cerro Mejía, parece que el palacio en Cerro Baúl pudo haber tenido un "hall de entrada", un área más accesible para interacciones de naturaleza semipública. $\mathrm{La}$ Unidad 25, en Cerro Baúl (Figura 8), localizada al oeste de la Unidad 9, es una plaza abierta con banquetas alrededor de sus cuatro muros y un gran nicho enterrado en el muro oeste. Este nicho pudo haber sido un lugar de honor para el administrador con más alta jerarquía asistente al evento en este hall de recepción o área de reuniones. El área de preparación para fiestas en la Unidad 7 puede también haber proporcionado comidas para las interacciones políticas entre comensales en esta área. Actualmente, la hipótesis que las fiestas fueron parte frecuente a cada estructura está basada más en las características y en el diseño de las estructuras que en las evidencias recuperadas. No hay duda que las actividades de fiesta fueron asociadas con un ritual intencional de cierre del elaborado componente de élite. La Unidad 25 en Cerro Baúl es un espacio de reunión semipúblico diseñado para facilitar la interacción directa o cara a cara, y pudo ser un área más formal que la Unidad 9 para el desarrollo de

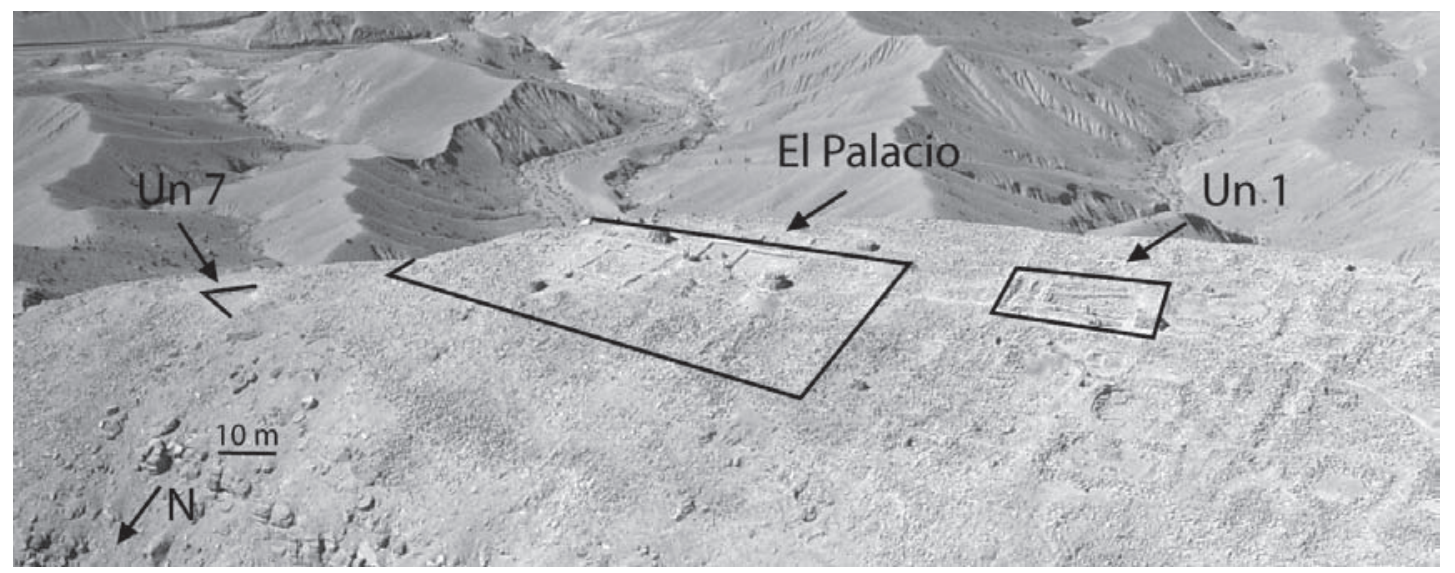

Figura 10. Foto de los sectores A y B en Cerro Baúl.

Photo of sectors A and B on Cerro Baúl. 
interacciones políticas entre comensales, la cual aparentemente se ubica en el centro de áreas de élite más privadas.

Es significativo que la Unidad 9 no tenga instalaciones para preparar los alimentos consumidos al interior del patio central de la residencia. Si comparamos el tamaño y la organización de la Unidad 9 en Cerro Baúl con aquellos de la Unidad 145 en Cerro Mejía podríamos esperar la presencia de áreas semejantes de preparación de comidas. Sin embargo, el contexto de este grupo patio al interior de un gran componente provincial presenta diferentes relaciones entre el personal encargado de la preparación de alimentos y los comensales, demostrando una importante diferencia en el acceso a la mano de obra y los recursos entre administradores provinciales y regionales. Si comparamos el tamaño de las Unidades 9 y 25 no existe una diferencia significativa, no obstante, dichas áreas se hallan dentro de la misma estructura $\mathrm{y}$ deben haber sido de alguna manera percibidas y usadas en diferentes formas.

\section{Una chichería estatal}

La Unidad 1 en Cerro Baúl contiene los restos de una gran área de producción de chicha y fragmentos de numerosas vasijas decoradas. La estructura consiste en un patio central de forma trapezoidal con cuartos rectangulares en sus cuatro lados (Figura 11). El patrón de abandono y el conjunto de artefactos asociados sugieren que fue un área especializada. Puede ser, sin embargo, que las casas tuvieron diferentes patrones de uso relacionados al estatus de los ocupantes asociados a la jerarquía política $\mathrm{o}$, que las diferencias entre los materiales reflejen transformaciones cronológicas en los roles del entorno residencial en las interacciones políticas. Esos temas requieren ser evaluados con más excavaciones y detallados análisis espaciales.

La Unidad 1 tiene un cuarto con una inusual forma de "L" que rodea el patio al este y al norte. La sección norte de este cuarto contiene un área de producción de chicha a gran escala. Semejante a la Unidad 145 en Cerro Mejía, los fogones asociados con hervir la chicha fueron elaborados con piedras. En este lugar, bloques de piedras grandes y rectangulares fueron colocados verticalmente. Espaciadas regularmente y paralelas al muro norte, dichas piedras sostuvieron al menos siete vasijas grandes. Basados en los fragmentos de vasijas rotas a propósito y recuperadas de los pisos de esta área, se estima que cada cántaro habría contenido de 120 a 140 litros de chicha (Moseley et al. 2005). Cada vasija tiene

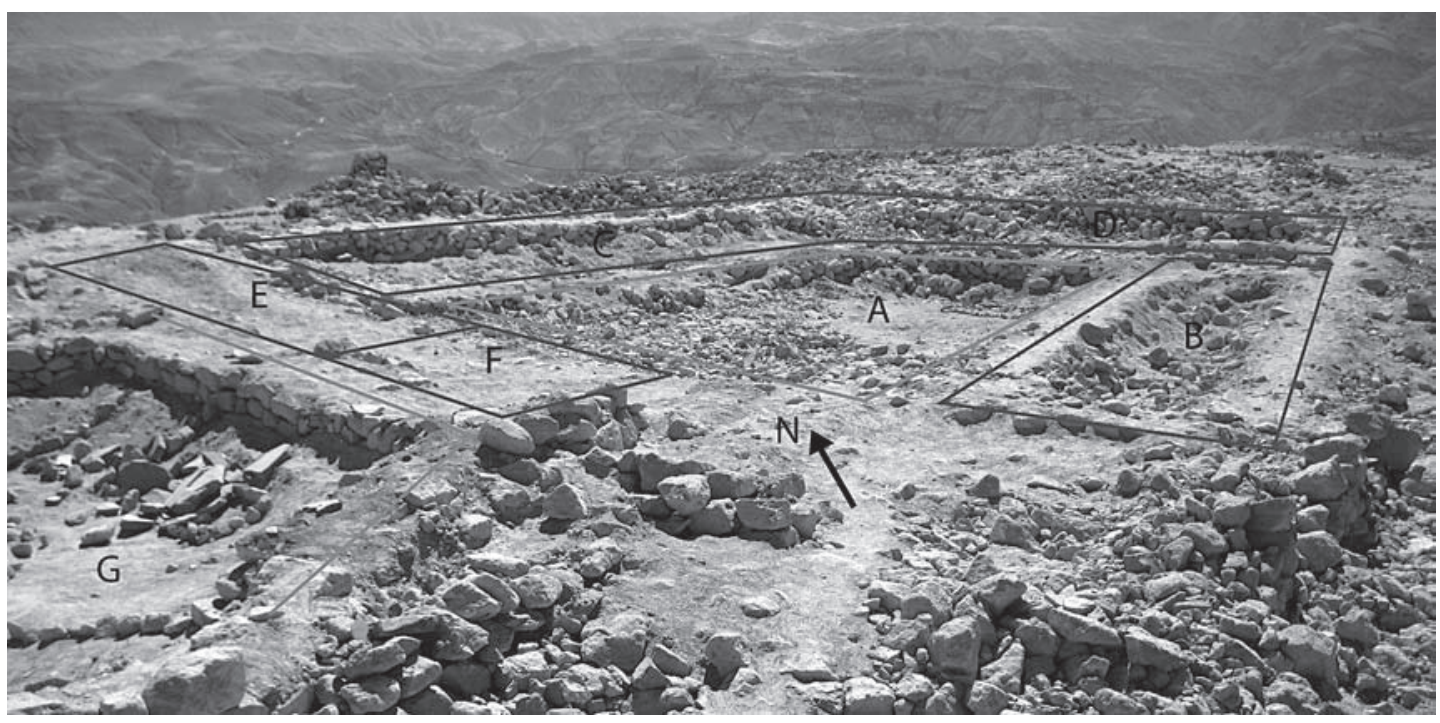

Figura 11. Foto de la chichería en el sector B del Cerro Baúl: (A) un patio trapezoidal donde la fermentación fue realizada; (B) un cuarto con piedras para la molienda; (C) el área de hervido de la chicha; (D) una posible área de almacenamiento; (E) un cuarto con batanes planos para molienda y evidencia de germinación de maíz $(\mathrm{F})$ y, $(\mathrm{G})$ una plaza con nichos en el muro este. Photo of the brewery in sector B of Cerro Baúl: (A) trapezoidal patio where fermentation took place; $(B)$ room with several grindstones; $(C)$ the area for boiling the chicha; $(D)$ a possible storage area; $(E)$ room with flat stone tables for grinding and evidence of corn germination $(F)$ and $(G)$ a plaza with niches in the eastern wall. 
un profundo hoyo de fogón a cada lado. Los restos de ceniza de dichos fogones contienen excremento quemado de cuy entre otros combustibles y basura de alta calidad -ofrendas potenciales-, las cuales, quizás, agregaron potencia a la bebida fermentada. Semejante a la Unidad 7, se almacenó molle en esta instalación y puede haber sido un ingrediente primordial de la chicha Wari de élite.

Los fragmentos de elaboradas vasijas decoradas se recuperaron de los cuartos de la chichería, los cuales fueron extensivamente quemados después del abandono. Las vasijas recuperadas representan la más fina colección de material cerámico excavado en Cerro Baúl. Los motivos representados en los pequeños cántaros y grandes queros son idénticos a los objetos recuperados en la capital y podrían ser importaciones ${ }^{5}$. Cuencos de este contexto asemejan convenciones Nazca, dónde los grandes queros representando la deidad frontal presentan ejecuciones estilísticas de algunos motivos que evidencian la influencia Tiwanaku (Feldman 1998; Williams y Nash 2002; Williams et al. 2003).

El patio de forma trapezoidal contenía los restos de 12 grandes cántaros a lo largo del muro norte. Dichas vasijas fueron interpretadas como vasijas para fermentación de abundante chicha (Feldman 1998). En consideración a la calidad y número de otras vasijas de cerámica, las cuales incluyen para consumo, tales como cuencos, un gran número de vasos y la producción a gran escala de chicha, la Unidad 1 fue claramente un lugar importante para celebrar fiestas. Sin embargo, aún no hemos descubierto dónde habrían ocurrido las relaciones entre comensales. Basados en la colección del material cerámico y el tamaño del área de producción de chicha parecería que las actividades en la Unidad 1 fueron claramente las más complejas que hasta el momento han sido recuperadas en la cima de Cerro Baúl.

\section{Interpretando las Evidencias de las Fiestas}

Las fiestas habrían sido un importante elemento en las relaciones sociopolíticas en el centro provincial Wari de Cerro Baúl, y otros asentamientos de colonos como Cerro Mejía. La preparación de fiestas y el desarrollo de eventos comensales fueron actividades planeadas en las unidades domésticas y en diferentes niveles en la jerarquía política. Asimismo, fueron parte de la planificación inicial de las casas así como del diseño original o agregado mediante remodelaciones mientras los dueños de casa ganaban estatus en la comunidad (Nash 2002). $\mathrm{El}$ hecho que algunas de esas ocasiones fueran relacionadas a la economía política del Estado Wari pueden ser inferidas a través del flujo de bienes, como regalos y tributos entre los niveles de jerarquía del asentamiento, incluyendo la cerámica Wari elaborada en Cerro Baúl, la obsidiana procedente de fuentes Wari y las cuentas elaboradas en piedras semipreciosas, pero que no fueron usadas en las casas de los pobladores de Cerro Mejía (Nash y Williams 2009).

La frecuencia de las fiestas en dichas áreas no puede ser determinada directamente, en vez de ello, pueden ser asociadas con la acumulación de desechos en los basurales. Pero los basurales son problemáticos porque es difícil relacionar los depósitos con el área donde se llevó a cabo la actividad. Los materiales derivados de dichos contextos pueden ser cuantificados, sin embargo, tales prácticas generan preocupación acerca de la validez de los cálculos basados en los volúmenes recuperados. Los basurales fueron quemados repetidamente, reduciendo el material orgánico a cenizas. Aunque la producción de chicha de molle proporciona evidencia en grandes cantidades de semillas disecadas en pozos estratificados y capas de depósitos de basura, la producción de chicha de maíz puede ser una ilusión arqueológica y se basa en el análisis de herramientas de piedra y sus residuos. Sin embargo, desde una perspectiva teórica, sugiero que un área no podría ser diseñada simplemente para un evento que determine su uso final, en vez de ello, cada área es designada en torno a actividades específicas y los modos principales de su uso (Nash 2002; Norberg-Schulz 1985; Rapoport 1990). El diseño de los espacios en cada uno de estos ejemplos refleja la anticipación y la planificación de reuniones así como las instalaciones para preparar los alimentos para grupos más allá de la unidad doméstica. Debido a que los espacios permitieron el desarrollo de actividades festivas, podemos concluir que dichas áreas fueron importantes para la reproducción de la unidad doméstica de algunos grupos. Además, debido a que los espacios para reuniones fueron hallados en habitaciones que varían en tamaño, riqueza y estatus sociopolítico, es posible que las fiestas y reuniones de pequeña escala hayan sido un importante elemento en la estrategia de administración Wari y en la economía política del Estado. 
Los contextos descritos y las escalas de reuniones y preparación de alimentos dentro de dichas esferas no están asociados con grandes fiestas de trabajo en la escala de una comunidad. Mientras que la chichería en Cerro Baúl pudo producir entre 800 a 1.000 litros por vez, no existen grandes áreas públicas en su cima que pudieran acomodar más de 100 a 120 personas. Es posible que ésta fuera transportada a otros lugares, pero es más probable que la chicha producida en Cerro Baúl fuera reservada para el consumo de las élites Wari y sus invitados. La escala de la producción en la Unidad 145 de Cerro Mejía fue sustancialmente menor y no pudo ser suficiente para una gran fiesta de trabajo. La plataforma de la plaza central pública ubicada en la cima de Cerro Mejía pudo ser un lugar importante donde grandes grupos se reunían para eventos, pero esto requiere mayor investigación. Si las áreas de preparación de fiestas a gran escala fueron directamente asociadas con el trabajo diario que apoyó la construcción de monumentales y extensos restos en Moquegua, dichos contextos aún no son descubiertos, quizás dichas construcciones fueron cubiertas mientras las construcciones progresaron. Alternativamente, es posible que las celebraciones a pequeña escala crearan obligaciones mientras que en ocasiones de trabajo los productos alimenticios hayan sido provistos a los trabajadores y preparados a nivel de unidades domésticas individuales. A pesar de ello, debemos considerar el rol de la mujer y cómo ellas, en las unidades domésticas de élite y en general, pudieron haber jugado un rol integral en la preparación de comidas a gran escala en los niveles bajos de la jerarquía sociopolítica.

Las relaciones de preparación de fiestas parecieran estar basadas en diferentes tipos de conexiones. En algunos casos aquellos que preparaban los alimentos parecen haber contribuido por una relación de parentesco, con los medios potenciales de movilizar la labor y recursos para grandes eventos comensales fueron basados, potencial y primariamente, entre mujeres de unidades domésticas a nivel de líderes de barrio. La labor empleada en los diferentes contextos descritos anteriormente pudo ser dirigida con una apropiada jerarquía de supervisión y, de ese modo, los grandes eventos de fiesta pudieron ser posibles. Aunque no han sido halladas evidencias de fiestas a gran escala en forma de grandes cocinas, es posible que varias cocinas pequeñas hayan sido usadas. Si éste fuera el caso, ¿cómo fueron percibidos estos eventos?, ¿de dónde provenían los recursos? y ¿quién presidió como anfitrión? son preguntas importantes que esperan mayores estudios. Por otro lado, en el palacio de Cerro Baúl es posible que los sirvientes hayan estado presentes. La chichería pudo también haber empleado a especialistas. De este modo, las fiestas en Cerro Baúl fueron sustentadas por diferentes relaciones sociales en comparación con las preparaciones de fiestas en Cerro Mejía. Esta diferencia fue, probablemente, muy importante y de seguro limitó la distancia social entre el patrocinador y el cliente en este sitio.

Ninguno de los contextos descubiertos hasta el momento pudo alimentar a un grupo de trabajadores significativo que modificaran el paisaje, cavaran el curso de un canal de $20 \mathrm{~km}$, o construyeran edificios de piedra a doble altura en la cima de una meseta a $600 \mathrm{~m}$ por encima de la fuente de agua más cercana para preparar mortero. Así, las reuniones a pequeña escala descritas anteriormente pudieron contribuir a dichos logros. Interacciones políticas a dicha escala habrían permitido el establecimiento, negociación o mantenimiento de relaciones asimétricas. El intercambio de bienes entre grupos pudo ser arreglado o ejecutado, las alianzas haber sido forjadas y la pertenencia a un grupo mantenida a través de rituales. Estas fiestas a pequeña escala habrían contribuido a logros de mayor envergadura y jugado un rol crucial en la integración de líderes entre ellos y con el Estado.

El consumo es uno de los aspectos de las interacciones y las relaciones creadas y desarrolladas en un evento comensal. Cómo diferentes anfitriones fueron provistos con alimentos y vasijas de servicio; qué gente contribuyó con su labor en la preparación de los alimentos; el tamaño del espacio usado para las fiestas y el número de personas que asistieron y sus relaciones con el anfitrión son atributos muy importantes que deben ser considerados. Cada uno de los espacios descritos anteriormente presenta diferentes instalaciones que jugaron un rol político en la sociedad Wari. El hecho que todas esas áreas fueran lugares de interacciones políticas entre comensales parece ser probable; sin embargo, la relación de actividades para alcanzar los objetivos de los administradores del Estado Wari constituye un asunto para futuras exploraciones y modelos teóricos. 
Agradecimientos: El financiamiento para el desarrollo de los programas de investigación en Cerro Baúl y Cerro Mejía ha sido proporcionado por la National Science Foundation (BCS-0226791 y BCS-9907167), la Heinz Family Foundation, la G. A. Bruno Foundation, la Asociación Contisuyo, The Field Museum y el Center for Latin American Studies at the University of Florida. Agradezco a mis colegas y asistentes que han trabajado conmigo a lo largo de muchos años buscando el entendimiento de la colonia Wari en Moquegua. Especialmente, quisiera agradecer a Ryan Williams, Michael Moseley y Susan deFrance por su colaboración y apoyo. Un agradecimiento especial a Emily Baca por traducir el presente manuscrito. A los evaluadores anónimos por sus valiosas sugerencias que contribuyeron a aclarar aspectos del texto y al trabajo de Pablo Espinoza por su edición del español. Finalmente quiero agradecer a la gente de Moquegua por participar con nosotros en el proceso de descubrir su gran pasado. Cualquier inexactitud en su interpretación es por supuesto de mi entera responsabilidad.

\section{Referencias Citadas}

Betanzos, J. de

1987 [1557] Narrative of the Incas. Traducido por R. Hamilton. University of Texas Press, Austin.

Bolin, I.

1998 Rituals of Respect: The Secret of Survival in the High Peruvian Andes. University of Texas Press, Austin.

Bourdieu, P.

1990 The Logic of Practice. Traducido por R. Nice. Stanford University Press, Stanford.

Brewster-Wray, C.

1989 Huari administration: a view from the capital. En The Nature of Wari, editado por R. Czwarno, F. Meddens y N. Morgan, pp. 23-33. BAR International Series 525, Oxford.

Bronk Ramsey, C.

2010 Oxcal v4.1.7. www.c14.arch.ox.ac.uk

Chacaltana Cortez, S. y D.J. Nash

2009 Los ofrendas como tradición de origen prehispánico: El caso de Cerro Baúl, valle alto de Moquegua. Actas del Simposio Internacional sobre Arqueología del Área Centro Sur Andina, editado por A. Belan Franco, M. Ziolkowski y J. Jennings. Universidad Católica de Santa María, Arequipa.

Cieza de León, $\mathrm{P}$.

1959 [1553] The Incas of Pedro de Cieza de León, editado por V. W. von Hagen, traducido por H. de Onis. University of Oklahoma Press, Norman.

Cook, A.

1987 The middle horizon ceramic offerings from Conchopata. Ñawpa Pacha 22-23:49-90.

2001 Huari D-shaped structures, sacrificial offereings and divine rulership. En Ritual Sacrifice in Ancient Peru, editado por E. Benson y A. Cook, pp. 137-163. University of Texas Press, Austin.

Cook, A. y M. Glowacki

2003 Pots, politics, and power: Huari ceramic assemblages and imperial administration. En The Archaeology and Politics of Food and Feasting in Early States and Empires, editado por T. Bray, pp. 173-202. Kluwer Academic, New York.

D'Altroy, T.

2001 From autonomous to imperial rule. En Empire and Domestic Economy, editado por T. D'Altroy y C. Hastorf, pp. 325-339. Kluwer Academic, New York.

D'Altroy, T. y T. Earle

1985 Staple finance, wealth finance, and storage in the Inka political economy. Current Anthropology 26:187-206.
deFrance, $\mathrm{S}$.

2004 Wari diet in Moquegua: the ordinary and the exotic. Ponencia presentada en la $69^{\text {th }}$ Annual Meeting of the Society for American Archaeology, Montreal.

Dietler, M.

2001 Theorizing the feast: rituals of consumption, commensal politics, and power in African contexts. En Feasts: Archaeological and Ethnographic Perspectives, editado por M. Dietler y B. Hayden, pp. 65-114. Smithsonian Institution Press, Washington D.C.

2003 Clearing the table: Some concluding reflections on commensal politics and imperial states. En The Archaeology and Politics of Food and Feasting in Early States and Empires, editado por T. Bray, pp. 271-282. Kluwer Academic, New York.

Dietler, M. y B. Hayden

2001 Digesting the feast: Good to eat, good to drink, good to think: An introduction. En Feasts: Archaeological and Ethnographic Perspectives on Food Politics and Power, editado por M. Dietler y B. Hayden, pp. 1-22. Smithsonian Institution Press, Washington, D.C.

Dietler, M. e I. Herbich

2001 Feasts and labor mobilization: Dissecting a fundamental economic practice. En Feasts: Archaeological and Ethnographic Perspectives on Food, Politics, and Power, editado por M. Dietler y B. Hayden, pp. 23-64. Smithsonian Institution Press, Washington D.C.

Evans, S.T.

2004 Aztec palaces and other elite residential architecture. En Palaces of the Ancient New World, editado por S.T. Evans y J. Pillsbury, pp. 7-58, Dumbarton Oaks Research Library and Collection, Washington, D.C.

Feldman, R.

1989 A speculative hypothesis of Wari southern expansion. En The Nature of Wari, editado por R. Czwarno, F. Meddens y N. Morgan, pp. 72-97. BAR International Series 525, Oxford.

1998 La ciudadela Wari de Cerro Baúl en Moquegua. En Moquegua: Los Primeros Doce Mil Años, editado por K. Wise, pp. 59-65. Museo Contisuyo, Moquegua.

Garcilaso de la Vega

1966 [1609] Royal Commentaries of the Incas and General History of Peru. Traducido por V. Livermore. University of Texas Press, Austin. 
Guaman Poma de Ayala, F.

1980 [1615] El Primer Nueva Coronica y Buen Gobierno. Editado por J.V. Murra y R. Adorno. Siglo Veintiuno, México.

Gero, J.

2001 Field knots and ceramic beaus: Interpreting gender in the Peruvian Early Intermediate Period. En Gender in Pre-Hispanic America, editado por C. Klein, pp. 15-55. Dumbarton Oaks, Washington D.C.

Isbell, B.J.

1978 To Defend Ourselves: Ecology and Ritual in an Andean Village. University of Texas Press, Austin.

Isbell, W.H.

1991 Huari administration and the orthogonal cellular horizon. En Huari Administrative Structure: Prehistoric Monumental Architecture and State Government, editado por W.H. Isbell y G. McEwan, pp. 293-316. Dumbarton Oaks, Washington D.C.

1997 Reconstructing Huari: A cultural chronology for the capital city. En Emergence and Change in Early Urban Societies, editado por L. Manzanilla, pp. 181-227. Plenum Press, New York.

Isbell, W.H., C. Brewster-Wray y L. Spickard

1991 Architecture and spatial organization at Huari. En Huari Administrative Structure: Prehistoric Monumental Architecture and State Government, editado por W.H. Isbell y G. McEwan, pp. 19-54. Dumbarton Oaks, Washington D.C.

Kaulicke, P. y T.D. Dillehay, editores

2008 Encuentros: Identidad, Poder y Manejo de Espacios Públicos. PUCP 9.

Kolata, A.

2003a The social production in Tiwanaku: Political economy and authority in a native Andean state. En Tiwanaku and its Hinterland: Archaeology and Paleoecology of an Andean Civilization, Volume 2 Urban and Rural Archaeology, editado by A. Kolata, pp. 449-472. Smithsonian Institution Press, Washington D.C.

2003b Tiwanaku ceremonial architecture and urban organization. En Tiwanaku and its Hinterland: Archaeology and Paleoecology of an Andean Civilization, Volume 2 Urban and Rural Archaeology, editado por A. Kolata, pp. 175-201. Smithsonian Institution Press, Washington D.C.

Lightfoot, R.

1993 Abandonment processes in prehistoric pueblos. En Abandonment of Settlement and Regions: Ethnoarchaeological and Archaeological Approaches, editado por C.M. Cameron y S.A. Tomka, pp. 162-177, Cambridge University Press, Cambridge.

McCormac, F.G., A.G. Hong, P.G. Blackwell, C.E. Buck, T.F.G. Higham y P.J. Reimer

$2004 \mathrm{SHCalO}_{4}$ southern hemisphere calibration 0-1000 cal BP. Radiocarbon 46:1087-1092.

McEwan, G.

1991 Investigations at the Pikillacta Site: A Provincial Huari Center in the Valley of Cuzco. En Huari Administrative Structure: Prehistoric Monumental Architecture and State Government, editado por W.H. Isbell y G. McEwan, pp. 93120. Dumbarton Oaks, Washington, D.C.

Meyerson, J.

1990 Tambo: Life in an Andean Village. University of Texas Press, Austin.
Morris, C.

1982 The infrastructure of Inka control in the Peruvian central highlands. En The Inca and Aztec States 1400-1800: Anthropology and History, editado por G. Collier, R. Resaldo y J. Wirth, pp. 153-171. Academic Press, New York.

1985 From principles of ecological complementarity to the organization and administration of Tawantinsuyu. En Andean Ecology and Civilization, editado por S. Masuda, I. Shimada y C. Morris, pp. 477-490. University of Tokyo Press, Tokyo.

Morris, C. y D.E. Thompson

1985 Huánuco Pampa: An Inca City and its Hinterland. Thames and Hudson, London.

Moseley, M.E.

1992 The Inca and their Ancestors. Thames and Hudson, London.

Moseley, M.E., R. Feldman, P. Goldstein y L. Watanabe

1991 Colonies and conquest: Tiahuanaco and Huari in Moquegua. En Huari Administrative Structure: Prehistoric Monumental Architecture and State Government, editado por W.H. Isbell y G. McEwan, pp. 121-140. Dumbarton Oaks, Washington D.C.

Moseley, M.E., D.J. Nash, P.R. Williams, S.D. deFrance, A. Miranda y M. Ruales

2005 Burning Down the Brewery: Establishing and Evacuating an Ancient Imperial Colony at Cerro Baúl, Peru. The Proceedings of the National Academy of Sciences 102: 17264-17271.

Murra, J.

1980 The Economic Organization of the Inka State. JAI Press, Greenwich, Connecticut.

1982 The mit'a obligations of ethnic groups to the Inka State. En The Inca and Aztec States 1400-1800: Anthropology and History, editado por G. Collier, R. Resaldo y J. Wirth, pp. 237-262. Academic Press, New York.

Nash, D.J.

2002 The Archaeology of Space: Places of Power in the Wari Empire. Doctoral Dissertation, Department of Anthropology, University of Florida, Gainesville.

2009 Households archaeology in the Andes. Journal of Archaeological Research 17:205-261.

Nash, D.J. y S. deFrance

s/f Plotting a Feast: Excavation and analysis of ritual remains in the Wari Palace on Cerro Baúl. Journal of Field Archaeology, manuscrito en poder de las autoras.

Nash, D.J. y P.R. Williams

2005 Architecture and power: relations on the Wari-Tiwanaku frontier. En The Foundations of Power in the Prehispanic Andes, editado por K. Vaughn, C. Conlee y D. Ogburn. Archaeological Papers of the American Anthropological Association No. 14.

2009 Wari provincial organization on the southern periphery. En Andean Civilization: A Tribute to Michael E. Moseley, editado por J. Marcus y P.R. Williams, pp. 257-276. Cotsen Institute of Archaeology Press, Los Angeles, Monograph 63.

Norberg-Schulz, C.

1985 The Concept of Dwelling: On the Way to Figurative Architecture. Electa Press, New York.

Ochatoma Paravicino, J. y M. Cabrera Romero 2002 Religious ideology and military organization in the iconography of a D-shaped ceremonial precinct at Conchopata. 
En Andean Archaeology II, editado por H. Silverman y W.H. Isbell, pp. 225-247. Kluwer Academic, New York.

Owen, B. y P. Goldstein

2001 Tiwanaku en Moquegua: interacciones regionales y colapso. Boletín de Arqueología, PUCP 5:169-188.

Rapoport, A.

1990 The Meaning of the Built Environment. Sage Publications, Beverly Hills.

Rostworowski de Diez Canseco, M.

1999 History of the Inca Realm. Traducido por H.B. Iceland. Cambridge University Press, Cambridge.

Rowe, J.

1946 Inca culture at the time of the Spanish conquest. En The Andean Civilizations, editado por J.H. Steward, Handbook of South American Indians, vol. 2, pp. 183-330. Bureau of American Ethnology, Bulletin 143, Smithsonian Institution, Washington D.C.

1982 Inca policies and institutions relating to cultural unification of the empire. En The Inca and Aztec States 1400-1800: Anthropology and History, editado por G.A. Collier, R.I. Rosaldo y J.D. Wirth, pp. 93-118. Academic Press, New York.

Schiffer, M.

1987 Formation Processes of the Archaeological Record. University of New Mexico Press, Albuquerque.

Schreiber, K.J.

1992 Wari Imperialism in Middle Horizon Peru. Anthropological Papers $N^{\circ} 87$, Museum of Anthropology, University of Michigan, Ann Arbor.

Stevenson, M.G.

1982 Toward an understanding of site abandonment behavior: Evidence from historic mining camps in southwest Yukon. Journal of Anthropological Research 1:237-265.
Underhill, A.

2002 Craft Production and Social Change in Northern China. Kluwer Academic Press, New York.

Wiessner, P.

2001 Of feasting and value: Enga feasts in a historical perspective. En Feasts: Archaeological and Ethnographic Perspectives in Food, Politics and Power, editado por M. Dietler y B. Hayden, pp. 115-143. Smithsonian Institution Press, Washington, D.C.

Williams, P.R.

1997 The Role of Disaster in the Development of Agriculture and the Evolution of Social Complexity in the South-Central Andes. Doctoral Dissertation, Department of Anthropology, University of Florida, Gainesville.

2001 Cerro Baúl: A Wari center on the Tiwanaku frontier. Latin American Antiquity 12:67-83.

Williams, P.R. y D.J. Nash

2002 Imperial interaction in the Andes: Wari and Tiwanaku at Cerro Baúl. En Andean Archaeology, editado por W.H. Isbell y H. Silverman, pp. 243-266. Plenum, New York.

Williams, P.R., D.J. Nash, M. Glowacki, R.J. Speakman, H. Neff, M.D. Glascock, M. Ruales M. y J. Clark

2003 Using INAA to assess Wari ceramic production and exchange on the Tiwanaku frontier. Ponencia presentada al $51^{\text {st }}$ International Congress of Americanists, Santiago.

Williams, P.R. y K. Sims

1998 Archaeological population estimates and agrarian productivity. Ponencia presentada al $97^{\text {th }}$ Annual Meeting of the American Anthropological Association, Philadelphia. EE.UU.

\section{Notas}

1 En este artículo emplearé 'Wari' para indicar a la polity y 'Huari' para indicar el sitio arqueológico.

2 Recientes excavaciones en Cerro Mejía no descritas en este artículo han revelado una clara evidencia que algunas de las personas viviendo en las laderas del sitio pertenecieron al área de Chuquibamba en el norte (departamento de Arequipa). Un entierro ubicado bajo el piso estuvo asociado a una 'placa pintada' que es un objeto mortuorio no hallado entre las comunidades del Periodo Formativo de Moquegua. Debido a la fuerte presencia Wari en Chuquibamba es posible que la gente de esta región haya sido animada a colonizar Moquegua o forzada a hacerlo durante la hegemonía Wari.

3 Recientes investigaciones del cuarto final de la chichería en Baúl (adyacente a la Unidad 1) revelaron evidencias para la germinación y molienda del maíz, de este modo, es muy probable que la chicha Wari fuera una mezcla de maíz y molle.

4 Un comentador del artículo ha sugerido que esas vasijas puedan haber sido rotas por grupos Estuquiñas tardíos que vivían en la cima de Cerro Baúl, sin embargo no hay ningún fechado radiocarbónico hasta el momento que corresponda con este periodo (ver Moseley et al. 2005 para una completo listado de los fechados para este sitio). No hay evidencia de ocupación durante el Intermedio Tardío, solo actividad ritual, la cual es fácilmente identificada como intrusiva (Chacaltana y Nash 2009). Basados en el arreglo de los restos durante las excavaciones, sugiero que los muros circundantes del patio fueron empujados para cubrir la tumba, y los restos de una ceremonia funeraria, quema de ofrendas, y depósitos rituales. Un artículo que detalla dichos restos está en preparación (Nash y deFrance s/f).

5 En 1998 Ismael Pérez fue tan amable de compartir fotos de las vasijas excavadas por él en el área donde se construyó el museo de sitio en Huari. De esta área Ismael Pérez halló grandes queros casi idénticos a aquellos de la chichería en Cerro Baúl (ver Moseley et al. 2005, figura 7). 